\title{
Multiple Effects of Phorbol Esters in the Rat Spinal Dorsal Horn
}

\author{
G. Gerber, ${ }^{a}$ I. Kangrga, P. D. Ryu, J. S. A. Larew, ${ }^{\text {b }}$ and M. Randic \\ Department of Veterinary Physiology and Pharmacology, lowa State University, Ames, lowa 50010
}

Spinal cord slice preparation and intracellular recording techniques were used to examine the effects of phorbol esters on the sodium- and calcium-dependent action potentials, the excitatory synaptic transmission, the basal (resting) and the dorsal root stimulation-evoked release of 9 endogenous amino acids, including glutamate and aspartate, and the responsiveness of the rat dorsal horn neurons to excitatory amino acids (glutamic, kainic, quisqualic, and $\mathrm{N}$-methyl-D-aspartic). 4- $\beta$-Phorbol-12, 13-dibutyrate and 4- $\beta$-phorbol-12, 13-diacetate produced minor alterations in membrane potential and resistance, but they broadened the sodiumdependent action potential and reduced the duration of the calcium-dependent action potential. In addition, phorbol esters caused a marked and long-lasting increase in the amplitude and the duration of excitatory postsynaptic potentials (EPSPs) evoked in dorsal horn neurons by orthodromic stimulation of a lumbar dorsal root. Phorbol esters produced a brief increase in the basal and electrically evoked release of endogenous excitatory (glutamic, aspartic) and inhibitory amino acids (glycine, GABA). In addition, the rates of release of alanine, serine, and threonine were also elevated. In the presence of TTX, phorbol esters selectively enhanced, in a reversible manner, the depolarizing responses of dorsal horn neurons to $\mathrm{N}$-methyl-D-aspartic acid and L-glutamate but not the responses to kainic or quisqualic acids. The potentiation of the NMDA response was blocked by APV, a specific NMDA receptor antagonist. Thus, phorbol esters appear to enhance excitatory synaptic transmission in the rat spinal dorsal horn slice preparation by acting both at pre- and postsynaptic sites. Phorbol esters could potentiate excitatory synaptic transmission by acting predominantly at a postsynaptic site (NMDA receptor), since the duration of the increased responsiveness of dorsal horn neurons to glutamate and NMDA correlates better with the enhancement of EPSPs than with the increased release of the stimulation-evoked glutamate and aspartate. The increased release of endogenous amino acids is consistent with a presynaptic (terminal) site of action, but it could also be explained by enhanced interneuronal activity. Although our results suggest that in the rat spinal dorsal horn protein kinase $\mathrm{C}$ may have a role in con-

\footnotetext{
Received Dec. 19, 1988; revised Mar. 15, 1989; accepted Mar. 28, 1989.

Supported by USPHS Grant NS 26352, NSF Grant BNS 8812172, and the U.S. Department of Agriculture.

Correspondence should be addressed to Prof. Mirjana Randic, M.D., Ph.D., at the above address.

a Present address: Department of Biochemistry and Biophysics, Iowa State University, Ames, IA 50010.

b Permanent address: Second Department of Anatomy, Semmelweis University, Medical School, Budapest, H-1450 Hungary

Copyright (C) 1989 Society for Neuroscience $0270-6474 / 89 / 103606-12 \$ 02.00 / 0$
}

trolling the release of putative excitatory and inhibitory neurotransmitters and may also be involved in the regulation of postsynaptic NMDA receptors, the identity of endogenous substance(s) participating in these effects is presently unknown.

It is presently an accepted idea that hydrolysis of membrane phosphoinositides is one means by which some neurotransmitters may mediate their actions at synapses (Berridge and Irvine, 1984; Nishizuka, 1984, 1986). One of the products of inositol phospholipid metabolism is 1,2-diacylglycerol (DAG), which has been shown to activate the calcium- and phospholipid-dependent protein kinase C (PKC) (Takai et al., 1979; Kishimoto et al., 1980; Nishizuka, 1984,1986). This action of diacylglycerol is mimicked by membrane-permeant, tumorpromoting phorbol esters (Castagna et al., 1982). When activated by DAG, or phorbol esters, the C-kinase phosphorylates specific substrate proteins that contribute to various cellular processes, including neurotransmitter release (Wu et al., 1982; Gispen et al., 1985; Nichols et al., 1987) and receptor-transducing mechanisms (Sorensen et al., 1981; Kristjansson et al., 1982; Rodnight and Perrett, 1986). PKC is present in high concentrations in the mammalian brain (Inoue et al., 1977; Takai et al., 1979), where it shows differential regional and cellular localization, with high levels in presynaptic terminals (Girard et al., 1985; Wood et al., 1986; Worley et al., 1986a, b; MochlyRosen et al., 1987).

Dicarboxylic amino acids, L-glutamate and L-aspartate, appear to be the major excitatory neurotransmitters in the mammalian brain and the spinal cord (Watkins and Evans, 1981; Mayer and Westbrook, 1987). The actions of the excitatory amino acids (EAAs) are mediated by at least 3 distinct receptor subtypes characterized on the basis of their responsiveness to selective agonists: $N$-methyl-D-aspartate (NMDA), quisqualate (QA), and kainate (KA).

The finding that the spinal dorsal horn contains high levels of binding sites for phorbol esters (Mantyh et al., 1984) and that $\mathrm{PKC}$ is present in the rat spinal dorsal horn (Worley et al., 1986a; Mochly-Rosen et al., 1987) raised the possibility that PKC may play a functional role in sensory transmission, both in the release of putative neurotransmitters and also in the signal transduction at various subclasses of EAA receptors. Since PKC activation can be mediated directly by phorbol esters, in the absence of phosphoinositide breakdown, we used these agents to examine the effects of the enzyme activation on passive and active membrane properties of rat spinal dorsal horn neurons, fast and slow excitatory synaptic transmission, basal and evoked release of endogenous excitatory (glutamate, aspartate) and inhibitory (GABA, glycine) amino acids, and the chemical sensitivity of 
various subclasses of EAA receptors of dorsal horn neurons to specific agonists. Preliminary reports of some aspects of this work have been published (Gerber et al., 1987, 1988).

\section{Materials and Methods}

Slices were obtained from Sprague-Dawley rats (14-32 d old) by using a technique that has been described in detail elsewhere (Murase and Randic, 1983; Urban and Randic, 1984). After the animal was anesthetized with ether, a segment of the lumbosacral (L5-S1) spinal cord was dissected out and sectioned with a Vibratome to yield several transverse slices or one horizontal slice, $300-400 \mu \mathrm{m}$ thick, with attached dorsal roots and ganglia. The horizontal slice was exclusively used in the release experiments. After the incubation for $1 \mathrm{hr}$ in oxygenated $\left(95 \% \mathrm{O}_{2}+5 \% \mathrm{CO}_{2}\right)$ control solution (in mM: $\mathrm{NaCl}, 124 ; \mathrm{KCl}, 5 ; \mathrm{KH}_{2} \mathrm{PO}_{4}$, $1.2 ; \mathrm{CaCl}_{2}, 12.4 ; \mathrm{MgSO}_{4}, 1.3 ; \mathrm{NaHCO}_{3}, 26 ;$ glucose, $10 ; \mathrm{pH} 7.4$ at $30 \pm$ $1{ }^{\circ} \mathrm{C}$ ), a slice was transferred into a recording chamber, where it was submerged beneath an oxygenated superfusing medium (flow rate about $3 \mathrm{ml} / \mathrm{min}$ ) containing lowered concentration of potassium ions $(1.9 \mathrm{mM}$ $\mathrm{KCl})$. The use of a high- $\mathrm{K}^{+}$solution during cutting and incubation of the slices seemed to improve their viability. The recording chamber had a capacity of $0.5 \mathrm{ml}$.

Conventional electrophysiological techniques were used for intracellular recording from and stimulation of dorsal horn neurons (laminae I-V) via a high-input-impedance bridge amplifier. Neurons were impaled, with fiber-filled glass microelectrodes that contained $4 \mathrm{M}$ potassium acetate $(\mathrm{pH} 7.2)$ and had DC impedances of $80-120 \mathrm{M} \Omega$, by oscillating the capacity compensation circuit of the amplifier (Dagan 8100 or Axoclamp 2). Cells were activated either directly with a DC current injection via the bridge circuit or synaptically by electrical stimulation of primary afferent fibers with a coaxial stainless-steel stimulating electrode (o.d. of inner and outer electrodes being 25 and $200 \mu \mathrm{m}$, respectively; Frederick Haer Co.) positioned on a lumbar dorsal root or dorsal root ganglia or by bipolar platinum electrodes positioned on the dorsal roots.

Stock solutions of phorbol esters [4 $\beta$-phorbol-12, 13-dibutyrate (PDBu) and $4 \alpha$-phorbol-12,13-didecanoate ( $4 \alpha$-PDiDec)] of $10^{-3} \mathrm{M}$ were made in dimethyl sulfoxide or in distilled water [4 $\beta$-phorbol-12,13-diacetate (PDAc)] and then frozen in aliquots to be used in single experiments. The aliquots were diluted in oxygenated Krebs solution prior to bath administration. Chemicals used and their sources were as follows: phorbol esters (Sigma), forskolin (Calbiochem), H-7 (1-5-isoquinolinesulfonyl-2-methylpipcrazinc dihydrochloride), and H-8 (N-2-methylamino-ethyl-5-isoquinolinesulfonamide dihydrochloride) (Seikagaku America), and D-2-amino-5-phosphonovaleric acid (Cambridge $\mathrm{Re}$ search Biochemicals, CRB, Sigma). L-Glutamate (Sigma, Peptides International), $N$-methyl-D-aspartate (CRB), KA (Sigma), and QA (CRB; Sigma) were applied extracellularly by positive pressure from micropipettes with tip diameters of 5-10 $\mu \mathrm{m}$. In the experiments where the chemical sensitivity of dorsal horn neurons to excitatory amino acids was tested, the bathing solution always contained TTX (Sigma) to block indirect synaptic interactions. Data were recorded on a Gould-Brush pen recorder (model 2200S) or stored on floppy disks by a Nicolet digital oscilloscope (model 4092) until processed and printed out onto a digital plotter.

In the release experiments, a horizontal slice was placed in one compartment of the 2-compartment chamber, where it was bathed in $1 \mathrm{ml}$ of the control solution. The dorsal roots with attached dorsal root ganglia were placed into the second compartment and immersed under the mineral oil. Lubriseal (Thomas Scientific) was used to ensure a leakproof, and also electrical, isolation between the 2 compartments. The dorsal roots were placed on 2 pairs of bipolar platinum electrodes; the distal pair was used for electrical stimulation and the proximal pair for recording of compound action potentials of the primary afferent fibers. The compound action potentials were monitored throughout the periods of stimulation and stored in a Tektronix (5113) oscilloscope and later photographed. Samples of perfusate $(1 \mathrm{ml})$ were collected at regular 10 min intervals before, during, and after stimulation of the dorsal roots or phorbol ester application. Samples were kept frozen at $-80^{\circ} \mathrm{C}$ until the derivatization and chemical analysis. Phorbol esters were applied into the slice perfusate for $10 \mathrm{~min}$ in known concentrations. The amino acid content in the samples was determined by high-performance liquid chromatography (HPLC) with fluorescence detection (Lindroth and Mopper, 1979). Prior to injection, aliquots of the perfusates were derivatized with $o$-phthaldialdehyde (OPA) 2-mercaptoethanol reagent.
Ethanolamine was added to each sample as an internal standard. Chromatography was performed on a $15 \mathrm{~cm}$ Adsorbasphere-OPA-HR column (Alltech Associates) using a pH 5.9 sodium acetate/THF/methanol gradient. Fluorescence was detected with a Kratos FS 950 fluorimeter. The amino acids measured came off the column in the following order: aspartate, glutamate, asparagine, serine, glutamine, glycine, threonine, alanine, and GABA. Results reported are the average of duplicate runs with each run lasting $31 \mathrm{~min}$.

\section{Results}

In this study we have used PDBu and PDAc, 2 phorbol analogs known to activate PKC. We also applied $4 \alpha-\mathrm{PDiDec}$, an analog that does not activate PKC (Castagna et al., 1982). A total of 59 dorsal horn neurons in laminae $\mathrm{I}-\mathrm{V}$ of the spinal dorsal horn was studied. The average resting membrane potential of these neurons was $65.0 \pm 0.8 \mathrm{mV}(\mathrm{m} \pm \mathrm{SEM})$, and the input resistance measured by hyperpolarizing pulses (0.1-1.8 nA of 100-650 msec duration) ranged from 25 to $100 \mathrm{M} \Omega$, the average value being $48.0 \pm 6.8 \mathrm{M} \Omega$.

Bath application of PDBu or PDAc $\left(10^{-8}-10^{-6} \mathrm{M}\right.$ for 3-20 min) caused a small $(4.7 \pm 0.5 \mathrm{mV})$ but prolonged $(22.4 \pm 4.7$ min) depolarization of the membrane potential in about $70 \%$ of tested cells. The onset of the cffect was rclatively slow; for instance, with $10^{-7} \mathrm{M}$ of PDBu the effect was first detectable after $8 \mathrm{~min}$ and reached the maximum after $10 \mathrm{~min}$ of the bath application. Washing with control medium for $30 \mathrm{~min}$ only partly reversed the effect. The phorbol ester-elicited depolarization was accompanied by a transient increase in the frequency and amplitude of the "spontaneous" postsynaptic potentials (Fig. 2A). The PDBu depolarization remained in the presence of TTX $\left(5 \times 10^{-7} \mathrm{M}\right)$ but was markedly reduced in a $\mathrm{Ca}^{2+}$-free solution. The inactive phorbol ester, PDiDec $(n=16)$ or the solvent DMSO $(n=5)$, caused no change in the membrane potential. In $16 \%$ of cells $(n=59)$ the depolarization was preceded by a slight initial hyperpolarization (about $1-2 \mathrm{mV}$ ) lasting between 1 and $5 \mathrm{~min}$. Whereas in about half of the tested neurons ( $n=28$ ) there was no apparent change in input resistance when measured within $30 \mathrm{~min}$ after phorbol ester application, a small increase $(14.7 \pm 2.8 \%)$ was observed in $36 \%$ and a small decrease $(10.6 \pm 2.1 \%)$ in $18 \%$ of the cells.

\section{Effects of phorbol esters on duration of sodium- and calcium- dependent action potentials}

It was previously determined that immature rat dorsal horn neurons have both sodium- and calcium-dependent action potentials (Murase and Randic, 1983). In 5 out of 11 neurons examined, the application of PDBu and PDAc $\left(5 \times 10^{-8}-10^{-6}\right.$ M) produced a small increase in the peak amplitude $(4.3 \pm 1.3 \%)$ and duration $(8.1 \pm 2.7 \%)$ of sodium spikes elicited by intracellularly injecting a brief $(10 \mathrm{msec})$ depolarizing current pulse. The spike broadening appeared to be due to slowing of the repolarizing phase of the action potential, while no significant changes in the rate of rise or the peak amplitude were detected (Fig. 1A). Similar findings were reported for CA1 hippocampal pyramidal cells (Storm, 1987). However, in cat spinal motoneurons, intracellular iontophoresis of PDAc or PKC increases the maximum rate of rise and the peak amplitude of the spike without evident change in resting potential and input resistance (Zhang and Krnjevic, 1987). The action potentials of rat dorsal horn neurons elicited by 5-10 msec depolarizing pulses are followed by at least 2 different afterhyperpolarizing potentials: (1) a fast afterhyperpolarization lasting about 2-5 msec and (2) a slow afterhyperpolarization lasting $25-100 \mathrm{msec}$. In agreement 
A

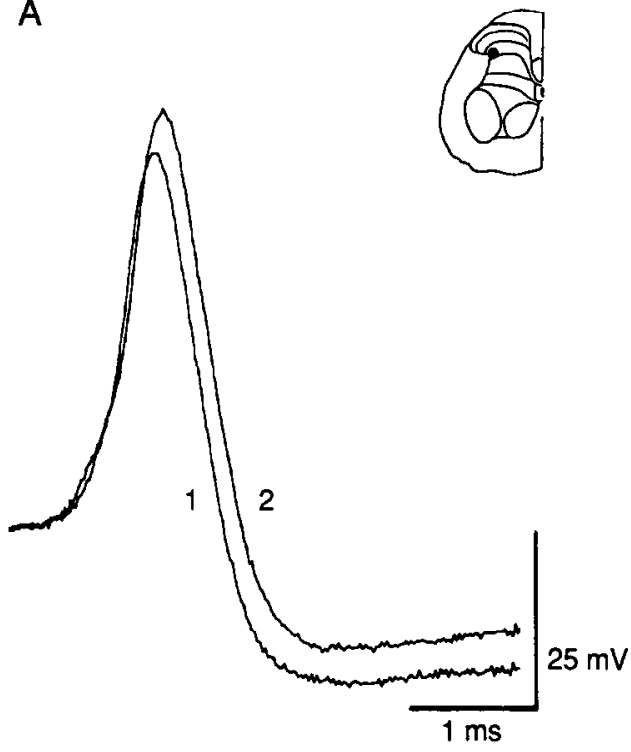

B

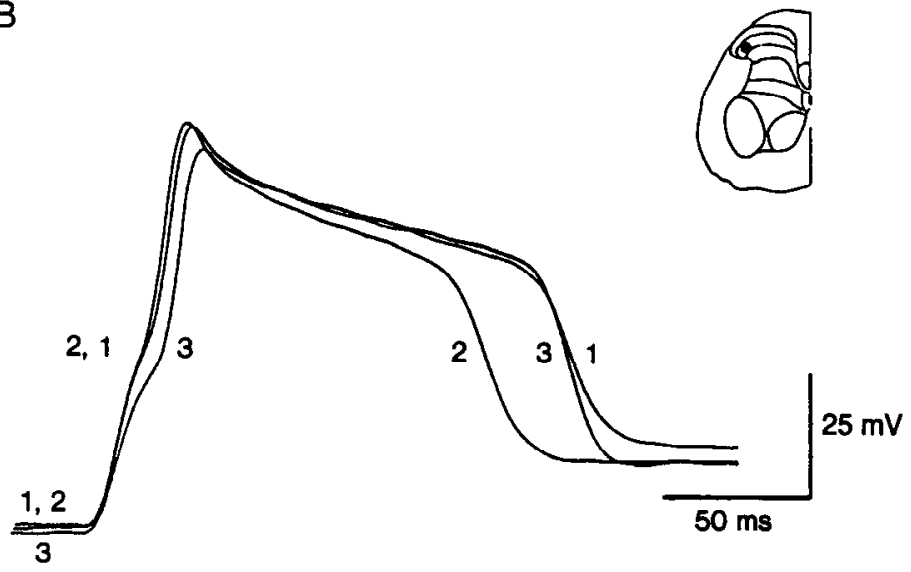

Figure 1. Effects of phorbol esters on sodium and calcium spikes. $A$, The sodium spike evoked by a depolarizing current pulse ( $0.12 \mathrm{nA}, 55 \mathrm{msec})$ was enhanced in amplitude and duration by $\mathrm{PDBu}, 10^{-7} \mathrm{M}$ for $3 \mathrm{~min}$. The effect occurred without evident change in resting potential, but there was a small decrease in membrane resistance (about $12 \%$ ). Control response $(l)$ and the response obtained 3 min after the onset of PDBu application (2) are superimposed. $B$, The effect of PDAc on Ca spike in a dorsal horn neuron bathed in a solution containing TTX $\left(5 \times 10^{-7} \mathrm{M}\right)$ and TEA (2 $\left.\times 10^{-2} \mathrm{M}\right)$. PDAc $\left(5 \times 10^{-5} \mathrm{M}\right.$ for $\left.40 \mathrm{sec}\right)$ produced a reversible decrease in the duration of Ca spike evoked with a depolarizing current pulse (0.8 $\mathrm{nA}, 30 \mathrm{msec}$ ) applied across the cell soma at regular (every $10 \mathrm{sec}$ ) intervals. Control response (I) and responses at 4 min (2) and $15 \mathrm{~min}(3)$ after the onset of the application of PDAc are shown. Resting membrane potential $V_{m}:-59 \mathrm{mV}, 15$-d-old rat $(A) ; V_{m}:-60 \mathrm{mV}$ (traces 1 and 2 ), -61 $\mathrm{mV}$ (trace 3), 19-d-old rat $(B)$. Insets show approximate locations of dorsal horn neurons determined by light microscopic inspection of the slices.

with the reports of other investigators (Baraban et al., 1985; Malenka et al., 1986b; Storm, 1987), the phorbol esters reduced the amplitude and duration of the slow afterhyperpolarization $(25.8 \pm 4.5 \%)$ in 7 out of 13 tested cells, while the fast afterhyperpolarization was not modified. In response to a $0.5 \mathrm{sec}$ depolarizing pulse dorsal horn neurons do not fire action potentials at a constant rate. Initial cluster of spikes is usually accompanied by a reduced rate of firing, i.e., accommodation. PDBu or PDAc $\left(5 \times 10^{-8}-10^{-6} \mathrm{M}\right)$ severely reducc spike frequency accommodation in a manner similar to that shown in hippocampal neurons (Baraban et al., 1985; Malenka et al., 1987). In $59 \%$ of examined cells $(n=17)$, the peak firing rate, during application of a depolarizing pulse $(0.1-0.8 \mathrm{nA}, 0.3-2$ sec), was increased by an average of $196.8 \pm 41.7 \%$.

When the slices were perfused with a control solution containing TTX $\left(5 \times 10^{-7} \mathrm{M}\right)$ to suppress the fast voltage-dependent sodium current and tetraethylammonium chloride (TEA, $2 \times$ $10^{-2} \mathrm{M}$ ) to reduce voltage-dependent potassium current(s), PDAc $\left(5 \times 10^{-5}-10^{-6} \mathrm{M}\right.$ for $\left.10 \mathrm{sec}-3 \mathrm{~min}\right)$ applied at resting membrane potential $\left(-60\right.$ to $-65 \mathrm{mV}$ ), reduced the duration of $\mathrm{Ca}^{2+}$-dependent action potential in 4 out of 5 tested cells (Fig. 1B). A similar result was reported in cultured spinal neurons (Werz and Macdonald, 1987). The decrease in the duration of Ca spike $(18.3 \pm 3.3 \%)$ was associated with a reduction in the amplitude of calcium-dependent plateau (Fig. $1 B$, trace 2). In the cell illustrated in Figure $1 B$, PDAc slightly increased the rate of rise and the peak amplitude of the Ca spike.

\section{Potentiation of excitatory synaptic transmission in the spinal} dorsal horn by phorbol esters

Application of PDBu or PDAc $\left(10^{-7}-10^{-6} \mathrm{M}\right)$ to a slice (stimulation site on a dorsal root was not exposed to phorbol esters) caused a marked and long-lasting increase in the amplitude of fast excitatory postsynaptic potentials (EPSPs) evoked in dorsal horn neurons by electrical stimulation of a lumbar dorsal root or dorsal root ganglia (Fig. $2 B$ ). In several cells, the EPSP grew large enough to trigger action potentials. The EPSPs were also potentiated by 1,2-oleoyl-acetylglycerol (OAG), another PKC activator (Fig. $2 \mathrm{C}$ ). The effect was present in $66 \%$ of tested cells $(n=15)$, where it often occurred in the absence or after a minimal change in membrane potential and input resistance. An avcrage cnhancement in the EPSP amplitude, recorded in response to suprathreshold stimulation of a lumbar dorsal root (6-10 V, 30-50 $\mu$ sec pulse duration), amounted to $206.6 \pm$ $44.8 \%$ (mean \pm SEM, $n=8$ ) in $37 \%$ of tested cells, whereas with the higher intensity stimulation $(15-25 \mathrm{~V}, 0.2-0.5 \mathrm{msec})$, the increase was smaller $(132.4 \pm 15.9 \%)$, being present in $46 \%$ of examined cells $(n=13)$. The half-duration of EPSPs increased on average by $70.0 \%( \pm 23.5 \%)$. The onset of the action of phorbol esters varied from 5-10 min in different dorsal horn neurons, and the effect usually lasted between 11 and $25 \mathrm{~min}$. Phorbol esters also enhanced the synaptic noise, spike discharge, and duration of the slow EPSP (Fig. 3, middle trace) recorded in response to high-intensity repetitive stimulation of a dorsal root (Urban and Randic, 1984).

In $32 \%$ of tested cells $(n=22)$, phorbol esters caused an increase in the frequency and amplitude of presumptive spontaneous EPSPs (Fig. 2A) and occasionally evoked spike discharge. The response could be generated by firing of previously silent afferent fibers or spinal interneurons. Inactive phorbol ester, $4 \alpha$-PDiDec $\left(10^{-7} \mathrm{M}\right)$, which was used as a control for both the active agent (PDBu) (Castagna et al., 1982) and the solvent (DMSO), did not modify either the frequency or the amplitude of "spontaneous" EPSPs. In addition, this phorbol analog did not cnhance the croked EPSPs.

Since the most common site responsible for alteration in syn- 
A

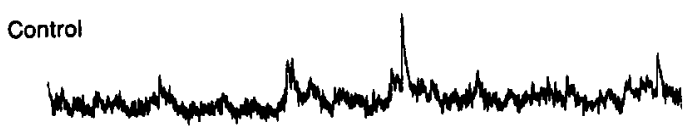

PDBu $10^{-7} \mathrm{M}$
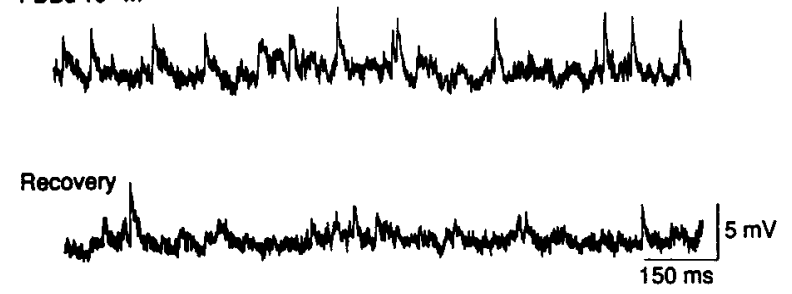

B

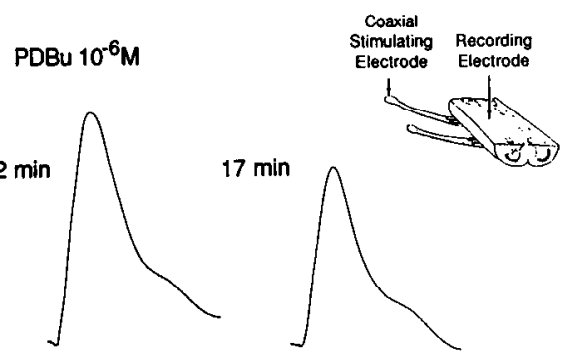

$10 \mathrm{~V}, 50$ us

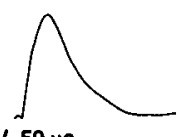

C

OAG $5 \times 10^{-5} \mathrm{M}$
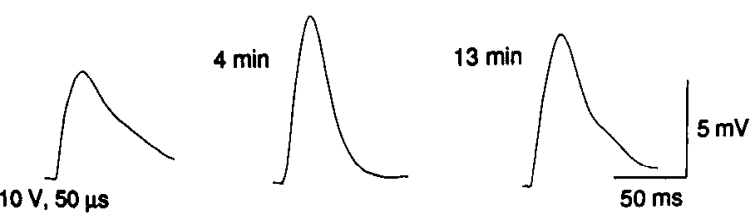

Figure 2. Phorbol esters enhance fast excitatory synaptic transmission. $A$, PDBu $\left(10^{-7} \mathrm{M}\right.$ for $\left.3 \mathrm{~min}\right)$ increases the frequency of presumptive spontaneous postsynaptic potentials. Control response (upper trace), responses at $10 \mathrm{~min}$ (middle trace), and $34 \mathrm{~min}$ (lower trace) after the onset of application of PDBu are shown. $V_{m}:-66 \mathrm{mV}$ (upper trace), $-64 \mathrm{mV}$ (middle trace) and $-62 \mathrm{mV}$ (lower trace), 17 -d-old rat. $B$, $\mathrm{PDBu}$ increases the intracellularly recorded excitatory postsynaptic potential EPSP. A coaxial stainless-steel stimulating electrode was placed on the lumbar dorsal root ganglion to orthodromically stimulate $(10 \mathrm{~V}$, $50 \mu \mathrm{sec}$ ) a dorsal horn cell (inset). Four EPSPs were averaged in each condition. Left trace represents control response; middle and right traces, responses at 2 and $17 \mathrm{~min}$ after the onset of the application of PDBu $\left(10^{-6} \mathrm{M}, 3 \mathrm{~min}\right)$, respectively. $V_{m}:-60 \mathrm{mV}$ (left and right traces), -59 $\mathrm{mV}$ (middle trace), 15-d-old rat. $C$, OAG increases the amplitude of EPSP evoked by orthodromic stimulation of the same dorsal horn neuron. Left trace represents control response; middle and right traces, responses obtained at 4 and $13 \mathrm{~min}$ after the onset of the application of OAG $\left(5 \times 10^{-5} \mathrm{M}\right.$ for $\left.3 \mathrm{~min}\right)$. $V_{m}$ : $-60 \mathrm{mV}$ (left trace), $-55 \mathrm{mV}$ (middle trace), and $-59 \mathrm{mV}$ (right trace). A decrease in input resistance $(7 \%$, middle trace $; 10 \%$, right trace) was observed.

aptic strength has been thought to be the presynaptic terminal, we have investigated the possibility of involvement of PKC in the modulation of the basal and dorsal root stimulation-evoked release of endogenous glutamate and aspartate (putative excitatory neurotransmitters) and GABA and glycine (putative inhibitory transmitters) by using phorbol esters in the horizontal spinal dorsal horn slice preparation having attached dorsal roots and ganglia. A more extensive analysis of these experiments will appear (Kangrga et al., 1989).

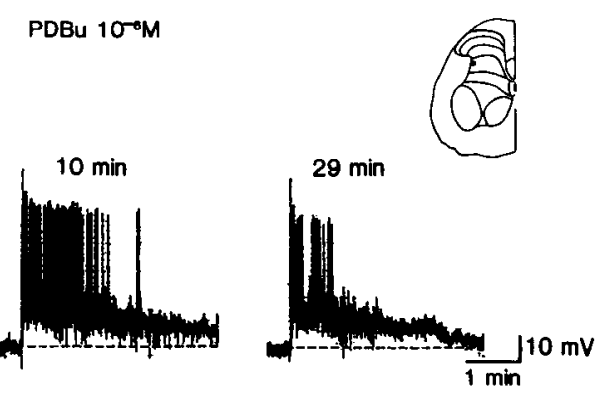

$5 \mathrm{~V}, 0.5 \mathrm{~ms}$

Figure 3. Phorbol esters modulate slow excitatory synaptic transmission in the rat spinal dorsal horn. PDBu $\left(10^{-6} \mathrm{M}\right.$ for $\left.13 \mathrm{~min}\right)$ increases the synaptic noise, spike discharge, and duration of a slow depolarizing potential recorded in response to a high-intensity repetitive electrical stimulation $(15 \mathrm{~V}, 0.5 \mathrm{msec}, 10 \mathrm{~Hz})$ of a lumbar dorsal rootlet. Left trace represents control response; middle and right traces, responses at 10 and $29 \mathrm{~min}$ after the onset of PDBu application. $V_{m},-60 \mathrm{mV}$ (left and right traces), $-58 \mathrm{mV}$ (middle trace), 15-d-old rat.

\section{Presynaptic modulation of the release of endogenous amino acids by phorbol esters}

The electrophysiological data presented suggest that phorbol esters can induce or increase the release of neurotransmitters in the rat spinal dorsal horn. Since excitatory synaptic transmission is augmented in the dorsal horn by phorbol esters, we examined the effects of phorbol esters on the release of 9 endogenous amino acids, including glutamate, aspartate, GABA, and glycine. Table 1 shows mean concentrations $(\mu \mathrm{M})$ in $10 \mathrm{~min}$ samples for the resting release of individual amino acids analyzed. Addition of $5 \times 10^{-7} \mathrm{M}$ PDiDec, a phorbol ester analog that does not activate PKC, had no effect on the basal release of 6 endogenous amino acids (Fig. $4 A$ ). However, in the presence of active phorbol esters, a significant, but transient (10 $\mathrm{min})$, increase in basal (Fig. $4 B$ ) and dorsal root stimulation-induced release (Fig. $4 C$ ) of endogenous glutamate, aspartate, and glycine from the spinal dorsal horn slice was observed. The rates of release of alanine, serine, and threonine were also elevated. The basal rate of asparagine was the least modified (Fig. $4 B$ ), whereas evoked release was reduced (Fig. $4 C$ ).

\section{Phorbol esters enhance the responsiveness of dorsal horn neurons to glutamate and NMDA}

Since "the spontaneous" EPSPs result not only from the spontaneous release of a neurotransmitter from the activated primary

\section{Table 1. Resting release of endogenous amino acids from horizontal} rat spinal dorsal horn slice into bath solution

\begin{tabular}{ll} 
Amino acid & $\begin{array}{l}\text { Resting release of amino } \\
\text { acids }\left(\mu \mathrm{M} / 10 \mathrm{~min}^{-1}\right)\end{array}$ \\
\hline Aspartate & $0.25 \pm 0.04$ \\
Glutamate & $0.51 \pm 0.09$ \\
Asparagine & $0.10 \pm 0.02$ \\
Glutamine & $7.20 \pm 1.40$ \\
Glycine & $1.21 \pm 0.20$ \\
GABA & $0.68 \pm 0.15$ \\
Serine & $1.10 \pm 0.15$ \\
Threonine & $0.60 \pm 0.07$ \\
Alanine & $1.29 \pm 0.27$
\end{tabular}

Values are means $\pm \operatorname{SEM}(n=10)$. 
A

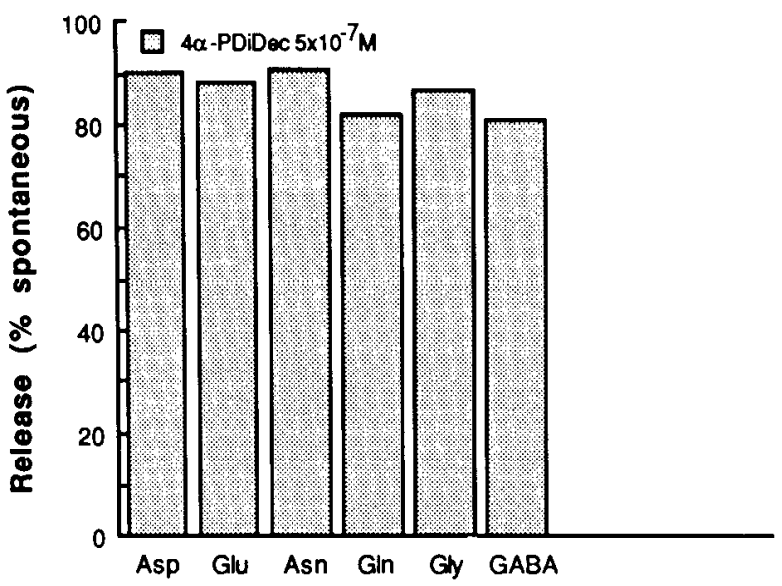

B

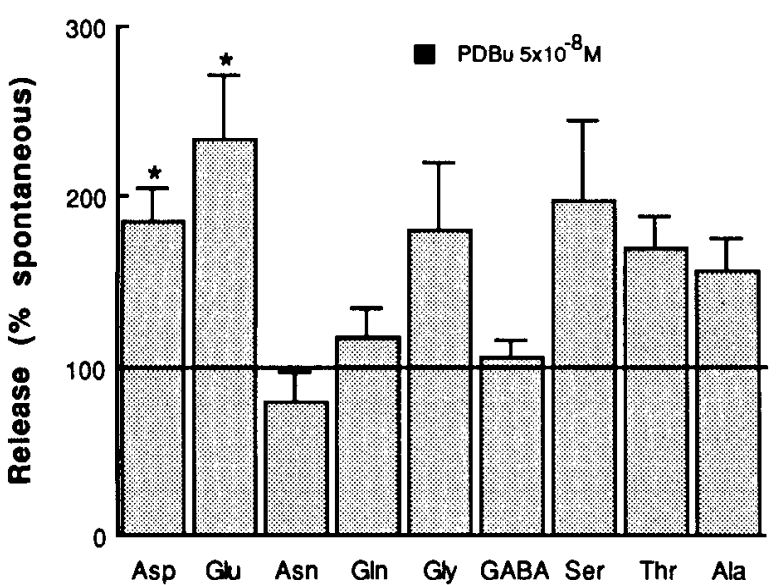

C

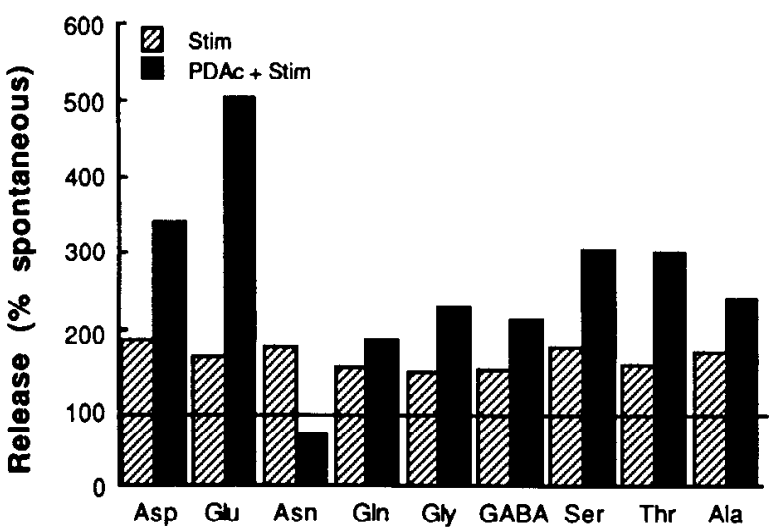

Figure 4. Phorbol esters enhance both basal and evoked release of endogenous amino acids. Column graphs of amounts of rates of release of endogenous amino acids during administration of phorbol esters in the rat horizontal spinal cord slice preparation are expressed as percentages of the average values measured during the 3 rest periods preceding the treatment. $A$, Addition of $4 \alpha$-PDiDec $\left(5 \times 10^{-7} \mathrm{M}, 10 \mathrm{~min}\right)$, a phorbol ester analog that does not activate PKC, had no effect on the basal release of 6 endogenous amino acids. $B$, Bath-applied PDBu ( $5 \times$ $10^{-8} \mathrm{M}, 10 \mathrm{~min}$ ) enhances the resting release of glutamate (Glu), aspartate (Asp), and glycine (Gly) in the spinal cord slice. In addition, the rates of release of serine (Ser), threonine (Thr), and alanine (Ala) were also elevated. The bars represent the SEM $(n=4)$. Significant $(p<0.05)$ changes are marked with asterisks. $C$, Phorbol esters produced a marked but transient increase of the dorsal root stimulation-evoked release of endogenous glutamate and aspartate. The rates of release of alanine, GABA, glycine, serine, and threonine were also elevated but to a smaller degree. A lumbar dorsal root was electrically stimulated ( $25 \mathrm{~V}, 40 \mu \mathrm{sec}$, $5 \mathrm{~Hz}$ for $5 \mathrm{~min}$ ) either in the absence (hatched columns) or in the presence of bath-applied PDAc $\left(5 \times 10^{-\prime} \mathbf{M}\right.$, black columns). Amounts of rates of release of various amino acids obtained during the stimulation pe- afferent fibers, but may also be a conscqucnce of the enhanced interneuronal activity, the amplitude histogram analysis of the mean amplitude of "spontaneous" EPSPs is not a reliable indicator of the site of action of phorbol esters in the spinal cord slice preparation. Because of this limitation in the amplitude analysis of "the spontaneous" EPSPs, another independent test for the possible interaction of active phorbol esters with the postsynaptic membrane of dorsal horn neurons was needed. An attempt was therefore made to investigate whether the stimulation of PKC by phorbol esters modulates the chemical sensitivity of the postsynaptic membrane of the rat dorsal horn neurons to EAAs. Since all tested dorsal horn neurons responded with depolarization of their membrane potential to QA and KA, and $94 \%$ of the cells to NMDA and L-glutamate, the effects of active phorbol esters on the postsynaptic depolarizing responses of dorsal horn neurons to EAAs (L-glutamic, $N$-methyl-D-aspartic, kainic and quisqualic) were examined.

When spinal dorsal horn slices bathed in a solution containing $1.3 \mathrm{~mm} \mathrm{Mg}^{2+}$ were exposed to PDBu $\left(10^{-7}-10^{-6} \mathrm{M}\right)$ or PDAc $\left(10^{-8}-10^{-7} \mathrm{M}\right)$, a selective increase in the sensitivity of the postsynaptic membrane of dorsal horn neurons to NMDA and L-glutamate was observed. As shown in Figure 5, PDAc increased the peak amplitude of the L-glutamate-induced depolarization (Fig. $5 A$ ) and both the amplitude and duration of the NMDA depolarization (Fig. $5 B$ ). When $\mathrm{Mg}^{2+}$ ions were removed from the hath medium, the enhancing effect of phorbol esters on the NMDA response was significantly increased, as illustrated in Figure $5 D$. The enhanced responsiveness of rat dorsal horn neurons to NMDA was antagonized by D-APV, the specific antagonist of the NMDA receptors (Fig. $5 F$ ). The effect of phorbol esters usually appeared within $2-13 \min (5.8 \pm 1.2, n=22)$ and outlasted the drug application by $26-47 \mathrm{~min}$ (Fig. 5, C, E). A threshold concentration for the detectable effect was $10^{-8} \mathbf{M}$. The increase in the NMDA sensitivity of the postsynaptic membrane appeared to be dose dependent in a single dorsal horn neuron but varied between different neurons. After washing with a control solution for more than $45 \mathrm{~min}$, the NMDA response in some cells almost fully recovered. A significant increase in the peak amplitude of the depolarizing potential induced by a fixed micropressure ejection of NMDA was found in 59\% of tested cells $(272.4 \pm 36.6 \%, n=22)$ and a smaller increase in the L-glutamate-induced depolarizing potential $(156.0 \pm 1.7, n$ $=8$ ) in $25 \%$ of the cells. In contrast to the findings with NMDA (Fig. 6, $A, C$ ), the postsynaptic depolarizations caused by local pressure microinjection of QA (Fig. $6 B, n=6$ ) and KA (Fig. $6 D, n=4$ ) were essentially unaffected after bath application of phorbol esters. For comparative reasons, 6 cells were tested with $4 \alpha$-PDiDec, a phorbol analog unable to activate PKC. While $4 \alpha$-PDiDec $\left(5 \times 10^{-7} \mathrm{M}\right)$ either did not induce any change or caused even a small decline in NMDA sensitivity (Fig. $7 B$ ), the NMDA response consistently increased after addition of active phorbol esters (Fig. 7A).

$\mathrm{H}-7$ is known to inhibit not only the enzymatic activity of PKC in vitro (Hidaka et al., 1984), but also that of cAMP- and cGMP-dependent kinases and calmodulin-dependent kinase (Nishizuka, 1984). Therefore, we tested the effect of $\mathrm{H}-7$ (10 $10^{-5}$

riods are expressed as percentages of the average values measured during the 3 rest periods preceding the stimulation. 

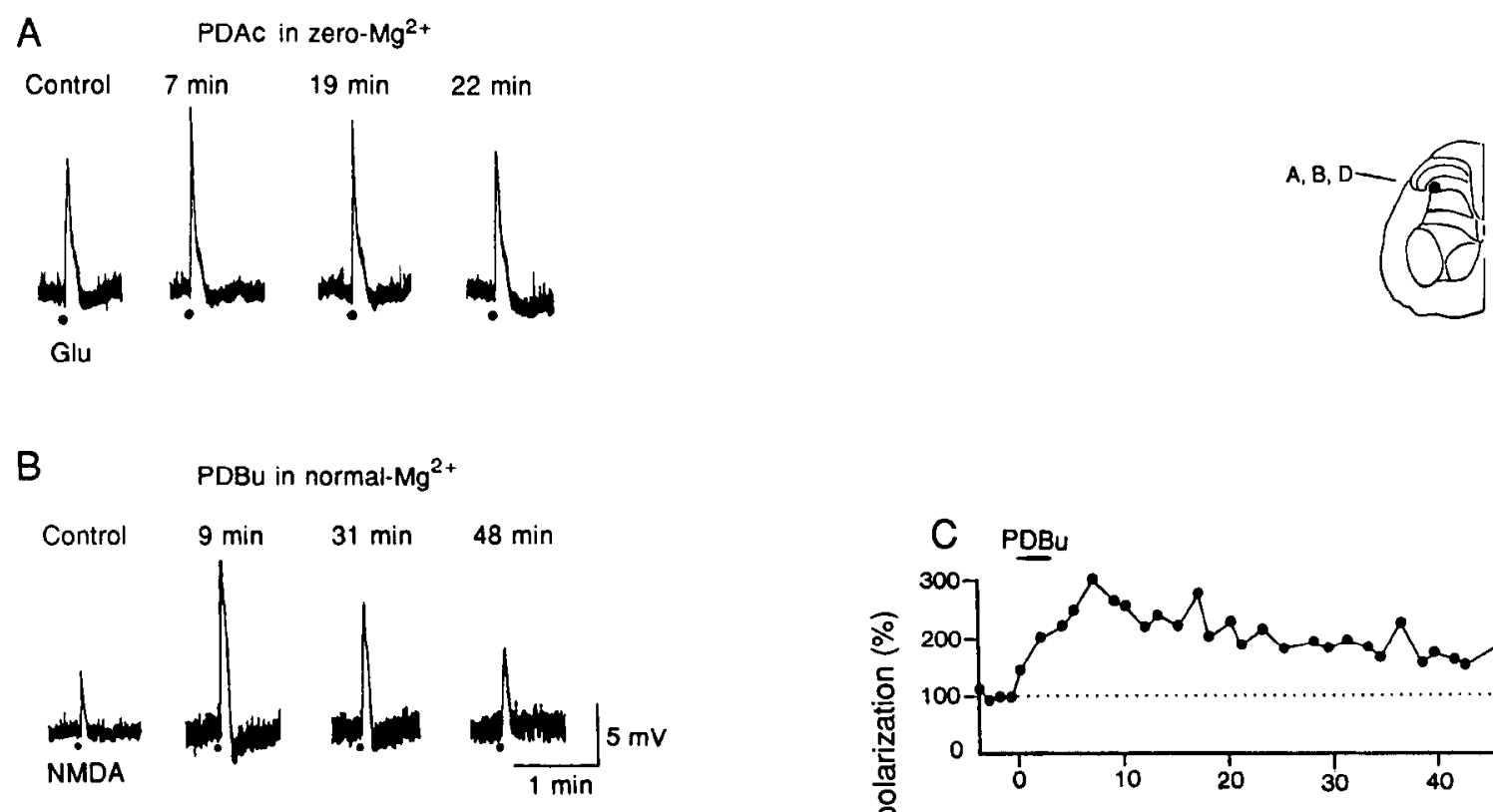

$\begin{array}{lll}\text { D } & \text { PDBu in zero }-\mathrm{Mg}^{2+} \\ \text { Control } & 4 \mathrm{~min} \quad 17 \mathrm{~min} & 25 \mathrm{~min}\end{array}$
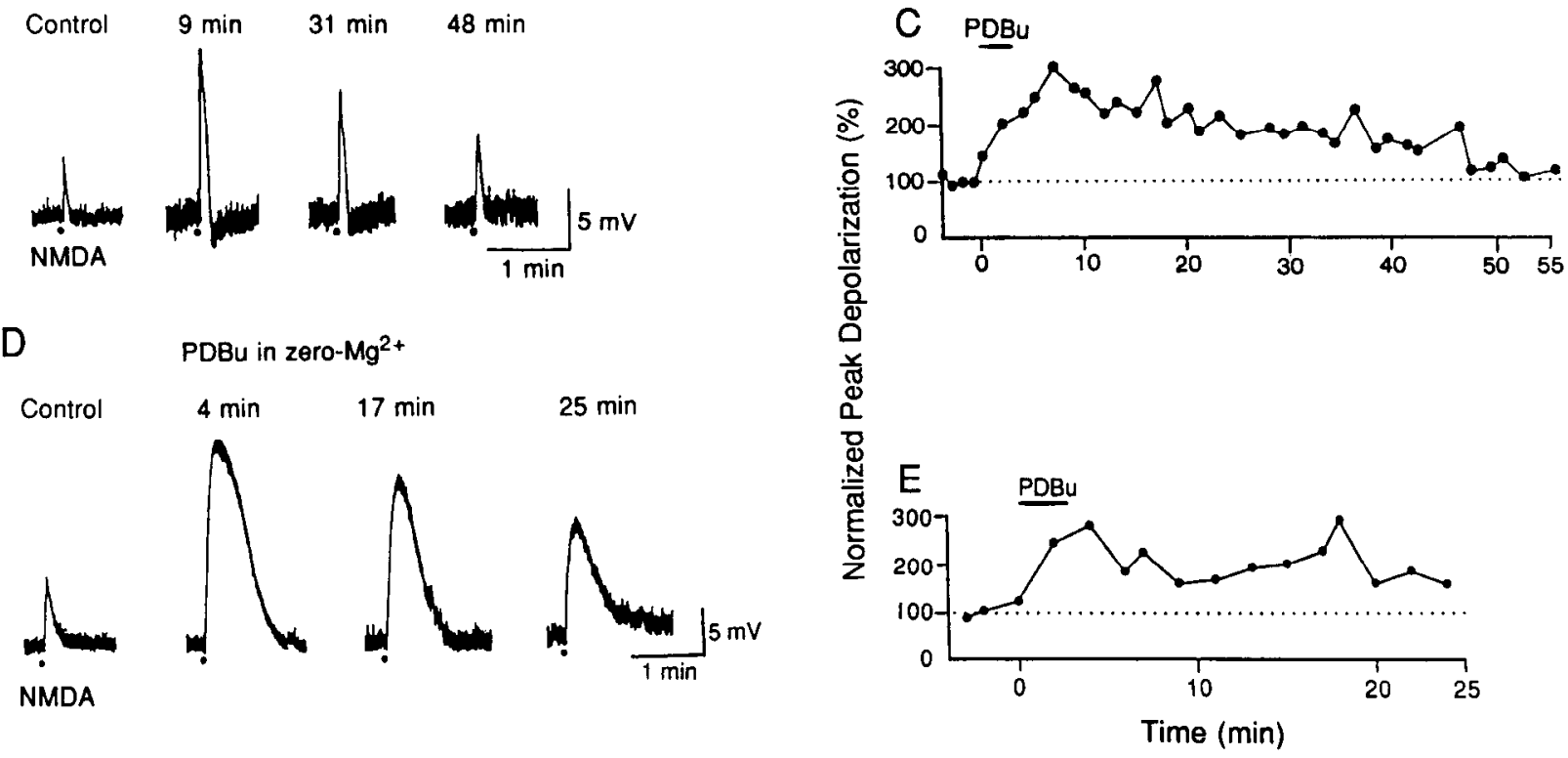

F
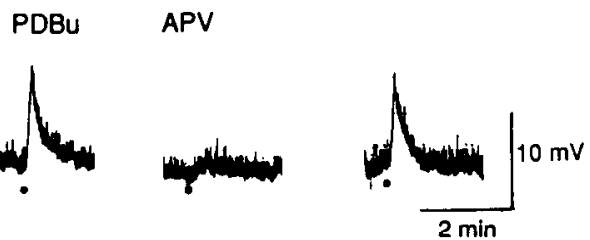

Figure 5. Phorbol esters increase sensitivity of dorsal horn neurons to L-glutamate and NMDA. In the presence of TTX $\left(5 \times 10^{-7} \mathrm{M}\right), \mathrm{PDAc}^{-1}\left(10^{-7}\right.$ M, $3 \mathrm{~min}$ ) augmented, in a reversible manner, the depolarizing response of a dorsal horn neuron to L-glutamate $(A)$ and, to a much greater degree, the depolarizing response of another neuron to NMDA $(B, C)$. Both amino acids were applied by positive pressure from micropipettes with tip diameters of $10 \mu \mathrm{m}\left(\mathrm{NMDA}, 10^{-3} \mathrm{M}, 3 \mathrm{sec}, 0.75 \mathrm{kPa}\right.$; Glu, $\left.5 \times 10^{-3} \mathrm{M}, 0.2 \mathrm{sec}, 0.47 \mathrm{kPa}\right)$ at 2 min intervals, at the times indicated by the dots below the traces. $A, V_{m}:-63 \mathrm{mV}$ (control), $-62 \mathrm{mV}\left(7,19\right.$, and $22 \mathrm{~min}$ after PDBu). $B, V_{m}:-63 \mathrm{mV}$ (control), $-61 \mathrm{mV}(9 \mathrm{~min}$ after PDBu), -57 $\mathrm{mV}(31 \mathrm{~min})$, and $-56 \mathrm{mV}(48 \mathrm{~min})$, 16-d-old rat. $C$, Graph shows normalized values of the peak depolarization obtained in $B$ plotted against the time. $D$, The enhancing effect of PDBu on the NMDA-induced depolarization is markedly increased when $\mathrm{Mg}^{2+}$ ions were removed from the cxternal medium. In the presence of TTX $\left(5 \times 10^{-7} \mathrm{M}\right)$, bath-applied PDBu $\left(5 \times 10^{-7} \mathrm{M}\right.$ for $\left.3 \mathrm{~min}\right)$ augmented, in a reversible manner, the NMDA depolarizing response. $V_{m}:-64 \mathrm{mV}$ (control), $-60 \mathrm{mV}(4 \mathrm{~min}),-61 \mathrm{mV}$ (17 and $25 \mathrm{~min}$ ). Input resistance, expressed as percentage in relation to control, was not modified at $4 \mathrm{~min}$ but decreased about $14 \%$ at $17 \mathrm{~min}$ after addition of PDBu. 17-d-old rat. $E$, Normalized peak depolarization recorded in the cell shown in $D$, plotted against the time. PDBu was applied at time 0 . Inset, Approximate locations of the examined cells. $F$, Potentiating effect of PDBu $\left(5 \times 10^{-7} \mathrm{M}, 3 \mathrm{~min}\right)$ on the NMDA response of a dorsal horn neuron bathed in a medium containing TTX $\left(5 \times 10^{-7}\right.$ M) was completely blocked by a specific NMDA antagonist, D-2-amino-5-phosphonovalerate (APV, $2.5 \times 10^{-4} \mathrm{M}$ ) in a reversible manner. 16-dold rat.

$2 \times 10^{-5} \mathrm{M}$ for $3 \mathrm{~min}$ ) to see whether the cnhancing effect of phorbol esters on the NMDA response can be antagonized. We found that the enhanced NMDA responsiveness of the rat dorsal horn neurons induced by PDAc was reversibly reduced in 3 out of 4 cells examined (Fig. 7C). The latter result may be a consequence of a reduction of the PKC activity, although other explanations may be sought since $\mathrm{H}-7$ is not a selective inhibitor of PKC enzyme (Nishizuka, 1984).

The enhanced responsiveness of dorsal horn neurons to
NMDA and glutamate could not be duc to a change in the membrane input resistance as the resistance was not affected, at least in about half of examined cells, by phorbol esters (Fig. $8 B$ ).

Forskolin enhances the depolarizing responses of dorsal horn neurons to $N M D A$

Although in the present work phorbol esters selectively augmented the depolarizing responses of dorsal horn neurons to 


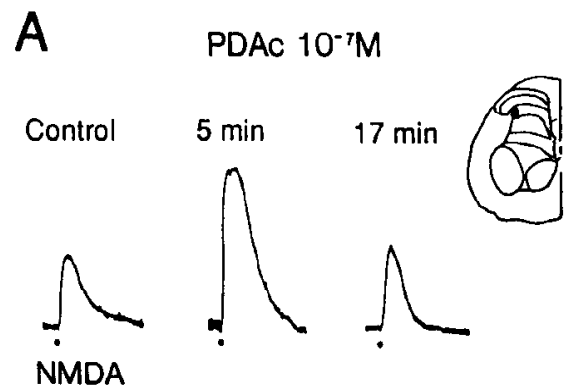

B

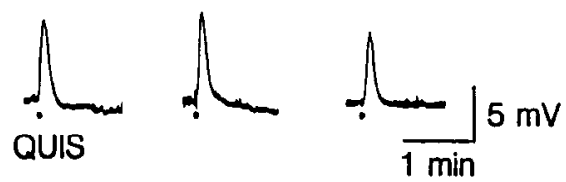

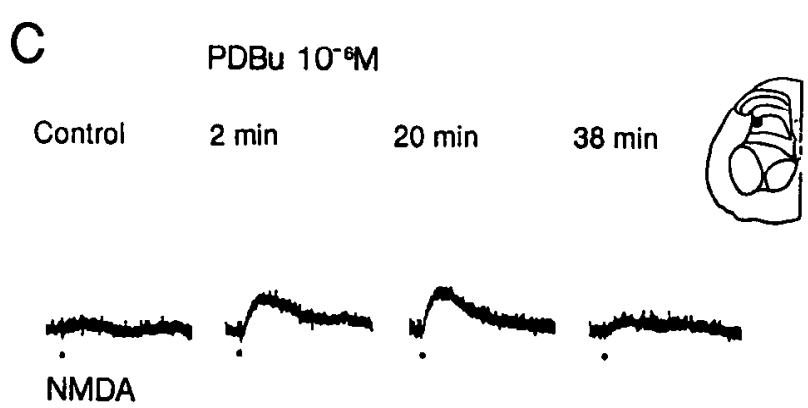

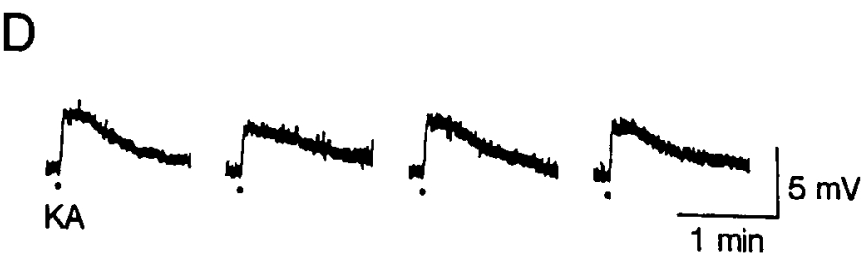

Figure 6. Effects of phorbol esters on sensitivity of 2 dorsal horn neurons to NMDA, quisqualate, and kainate. In the presence of TTX $\left(5 \times 10^{-7}\right.$ $\mathrm{M})$, bath-applied PDAc $\left(10^{-7} \mathrm{M}, 3 \mathrm{~min}\right)$ enhanced the depolarizing response of a dorsal horn neuron to NMDA $(A)$, while the quisqualate (QUIS)induced response was not significantly modified $(B)$. First traces show control responses; second, the responses recorded at 5 min; and third, at 17 min after the onset of the bath application of PDAc. Both amino acids were applied alternatively by pressure ejection (NMDA, $10^{-3} \mathrm{M}, 0.4 \mathrm{sec}$, $0.47 \mathrm{kPa}$; QUIS, $10^{-4} \mathrm{M}, 0.1 \mathrm{sec}, 0.47 \mathrm{kPa}$ ) at $3 \mathrm{~min}$ intervals. $A: V_{m},-78 \mathrm{mV}$ (control), $-75 \mathrm{mV}(5 \mathrm{~min}$ after PDAc), and $-74 \mathrm{mV}(17 \mathrm{~min})$. $B$ : $V_{m,}-78 \mathrm{mV}$ (control), $-76 \mathrm{mV}(5 \mathrm{~min})$, and $-74 \mathrm{mV}\left(17 \mathrm{~min}\right.$ after PDAc). 19-d-old rat. $C$ and $D$, in the presence of TTX $\left(5 \times 10^{-7} \mathrm{M}\right)$, PDBu $\left(10^{-6} \mathrm{M}, 3 \mathrm{~min}\right)$ augmented in a reversible manner the depolarizing response of a dorsal horn neuron to NMDA $(C)$, while the response to kainate (KA) was not modified $(D)$. Amino acids were applied alternatively by pressure ejection (NMDA, $10^{-3} \mathrm{M}, 0.2 \mathrm{sec}, 0.39 \mathrm{kPa} ; \mathrm{KA}, 10^{-3} \mathrm{M}, 0.7 \mathrm{sec}$, $0.39 \mathrm{kPa}$ ) at $3 \mathrm{~min}$ intervals. $C$ and $D: V_{m},-75 \mathrm{mV}$ (control), $-78 \mathrm{mV}(2 \mathrm{~min}),-76 \mathrm{mV}$ (20 and $\left.38 \mathrm{~min}\right)$. 18-d-old rat. Neuronal input resistance decreased about $15 \%$ at 2 min, but was not modified at 20 and 38 min after addition of PDBu.
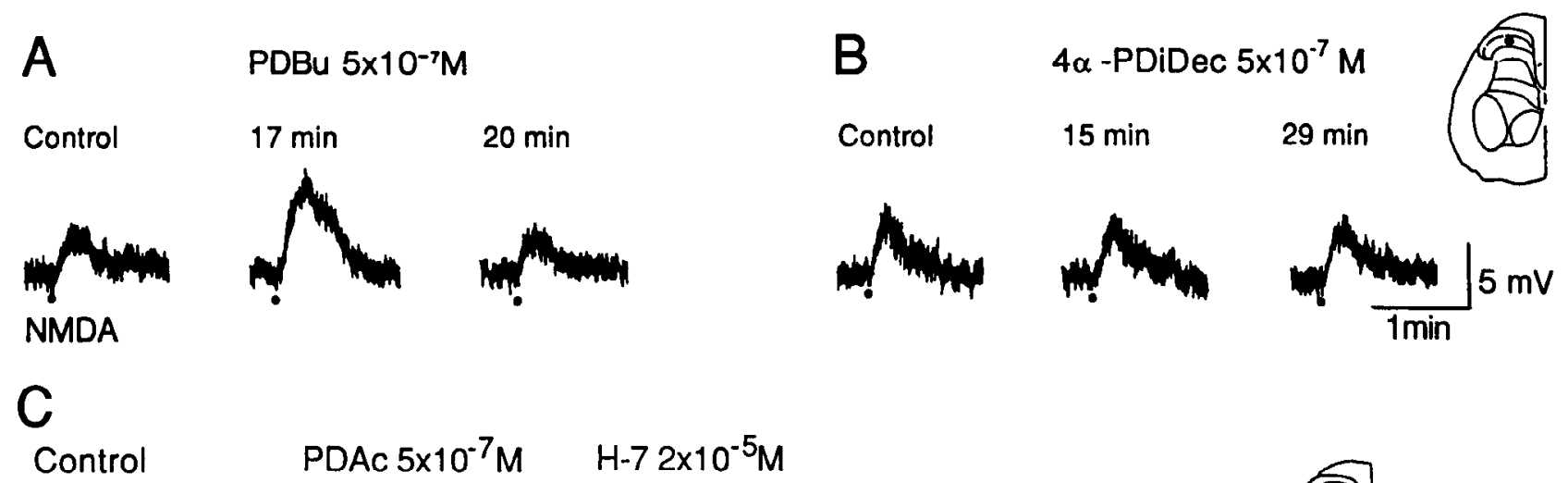

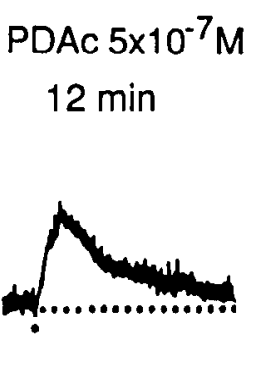
$H-72 \times 10^{-5} \mathrm{M}$ $18 \mathrm{~min}$
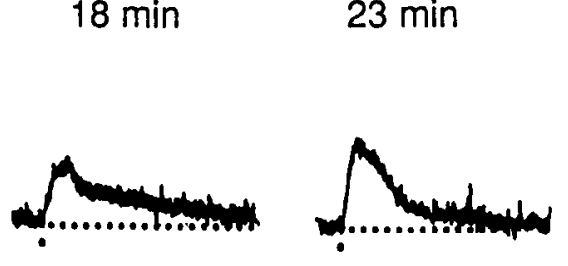

$40 \min$
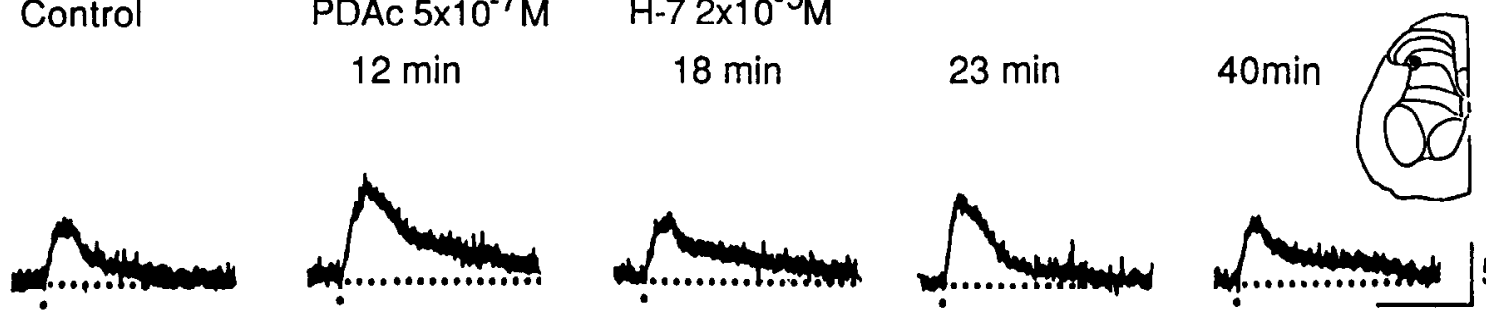

NMDA

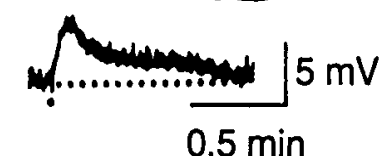

Figure 7. Inactive phorbol ester does not modulate sensitivity of a dorsal horn neuron to NMDA (B). H-7 inhibits the enhancing effect of PDAc on the NMDA-induced depolarization of a dorsal horn neuron in a reversible manner $(C)$. In the presence of TTX $\left(5 \times 10^{-7} \mathrm{M}\right)$, bath-applied $\mathrm{PDBu}\left(5 \times 10^{-7} \mathrm{M}, 3 \mathrm{~min}\right)$ augmented in a reversible manner the depolarizing response of a dorsal horn neuron to NMDA $(A)$, while the inactive phorbol ester, $4 \alpha$-PDiDec $\left(5 \times 10^{-7} \mathrm{M}, 3 \mathrm{~min}\right)$, was ineffective in the same cell $(B)$. NMDA was applied by pressure ejection $\left(10^{-3} \mathrm{M}, 0.2 \mathrm{sec}, 0.47\right.$ $\mathrm{kPa}$ ) at $2 \mathrm{~min}$ intervals. $A: V_{m},-70 \mathrm{mV}$ (control), $-67 \mathrm{mV}$ (17 and $20 \mathrm{~min}$ after PDBu). $B: V_{m},-70 \mathrm{mV}$ (control), $-74 \mathrm{mV}(15 \mathrm{~min})$, and -78 $\mathrm{mV}$ (29 min after PDiDec). 16-d-old rat. C, First trace shows control response; second trace, response recorded $12 \mathrm{~min}$ after the application of PDAc $\left(5 \times 10^{-7} \mathrm{M}, 3 \mathrm{~min}\right)$; third trace, response recorded $4 \mathrm{~min}$ after bath-administration of $\mathrm{H}-7\left(2 \times 10^{-5} \mathrm{M}, 3 \mathrm{~min}\right)$; fourth trace, response 23 min after PDAc and $9 \mathrm{~min}$ after H-7; ffth trace, response $40 \mathrm{~min}$ after PDAc and $26 \mathrm{~min}$ after H-7 application. NMDA was applied by pressure ejection (NMDA $10^{-3} \mathrm{M}, 0.2 \mathrm{sec}, 0.39 \mathrm{kPa}$ ). $V_{m},-63 \mathrm{mV}$ (control), $-62 \mathrm{mV}$ (all other traces). Inset, Approximate locations of the tested cells. $21-$ d-old rat. 


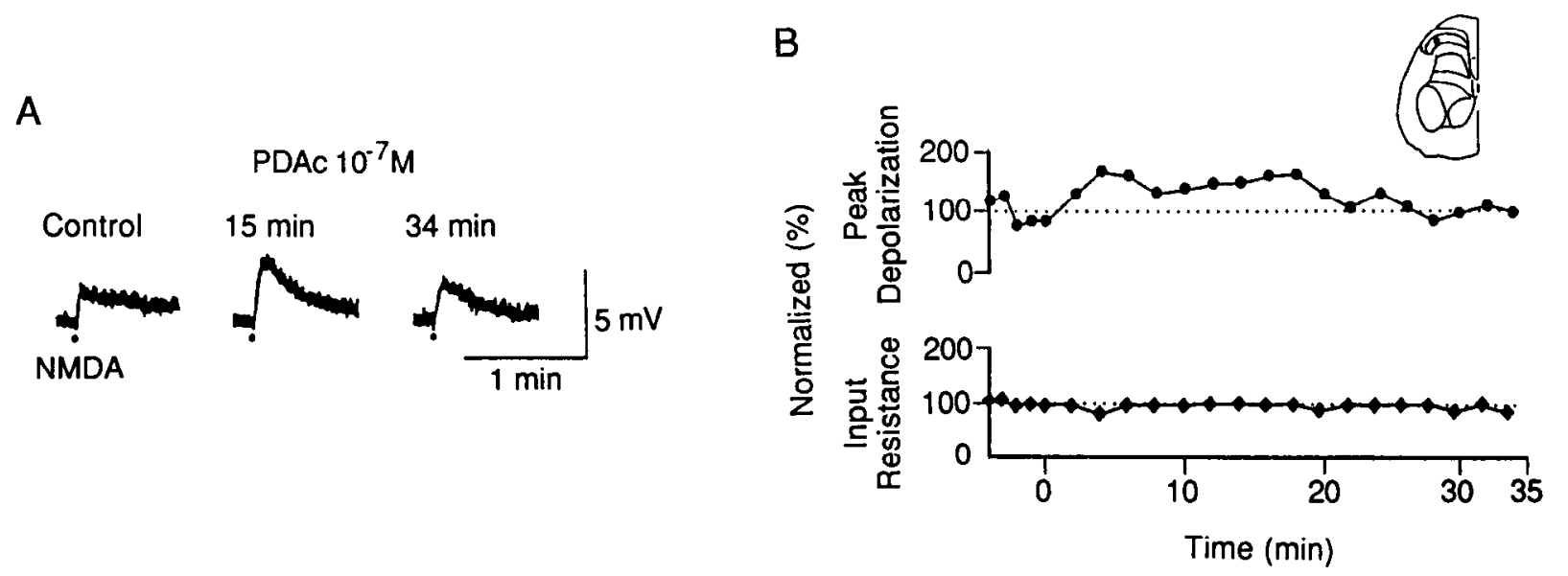

Figure 8. Enhancing effect of PDAc on the NMDA depolarization is not associated with a change in input resistance. A, Left trace is a control response; middle and right traces, responses recorded 15 and $34 \mathrm{~min}$ after the bath application of PDAc (10-7 $\mathrm{M}$ for $3 \mathrm{~min})$, respectively. $B, U p p e r$ graph shows the normalized peak depolarization recorded in the same neuron in response to NMDA plotted against time; lower graph, normalized values of input resistance plotted against time. PDAc was applied at $0 \mathrm{~min}$. NMDA was applied by pressure ejection (NMDA $10^{-3} \mathrm{M}, 0.5 \mathrm{sec}, 0.45$ $\mathrm{kPa})$. Inset, Approximate location of the tested cell. $V_{m},-65 \mathrm{mV}$. 19-d-old rat.

NMDA, the identity of endogenous substance(s) participating in this effect is presently unknown. The fact that PKC has nonneuronal localization in the rat spinal dorsal horn (MochlyRosen et al., 1987) makes its direct involvement less likely. Therefore, attempts are currently undertaken to seek candidates for endogenous activators in other second-messenger neuronal systems that may be influenced by administration of PKC activators (Berridge, 1987). There are many reports indicating that phorbol esters have effects on cAMP metabolism in mammalian tissues (Bell et al., 1985; Hollingsworth et al., 1985; Rozengurt et al., 1987). PDAc also augments accumulation of cAMP elicited by forskolin (Rozengurt et al., 1987). It is therefore of interest that we observed 3 cells $(n=5)$ in which the bath-administration of forskolin $\left(2.5-5 \times 10^{-5} \mathrm{M}\right.$ for $\left.3 \mathrm{~min}\right)$, an adenylate cyclase activator, enhanced the sensitivity of the NMDA receptors of the immature rat dorsal horn neurons (Fig. 9). The enhancing effect of forskolin was reduced by a claimed antagonist (Hidaka et al., 1984) of cAMP-dependent protein kinase, H-8 (2 $\times 10^{-5} \mathrm{M}$ for $3 \mathrm{~min}$ ), but not by $\mathrm{H}-7$. The latter result is surprising since $\mathrm{H}-7$ is supposed to be as effective in blocking protein kinase A as PKC activity (Hidaka et al., 1984). Since the latter result represents an observation obtained from a small sample of dorsal horn cells, and in view of possible non-adenylate cyclasemediated effects of forskolin, an extensive analysis of the effects of cyclic nucleotides on the responsiveness of dorsal horn neurons to EAA has been recently undertaken and will be reported separately.

\section{Discussion}

The results presented in this paper indicate that activators of PKC, phorbol esters, and OAG enhance the excitatory synaptic transmission in the rat spinal dorsal horn by acting at pre- and postsynaptic sites (Gerber et al., 1987, 1988). The increase in the amplitude of the EPSP in the absence of significant changes in resting membrane potential or neuronal input resistance of the dorsal horn neurons could be due to a presynaptic effect to increase the amount of the released transmitter. However, it could also be due to a postsynaptic effect since we have shown that phorbol esters and OAG increased the postsynaptic responses of dorsal horn neurons to glutamate and NMDA.
Yamamoto (1988) recently reported that OAG and 12-O-tetradecanoylphorbol-13-acetate (TPA) potentiate the glutamatemediated excitatory synaptic transmission at the insect neuromuscular junction, the latter being the best characterized example of the synapse mediated by glutamate (Usherwood, 1978; Yamamoto and Washio, 1980). However, Yamamoto's (1988) and our findings are inconsistent with the results obtained in the rat hippocampal slice preparation (Malenka et al., 1986a,b, 1987) and the frog neuromuscular junction (Shapira et al., 1987), where phorbol esters augmented transmitter release without affecting the sensitivity of postsynaptic receptors to glutamate (Malenka et al., 1986a) or ACh (Shapira et al., 1987).

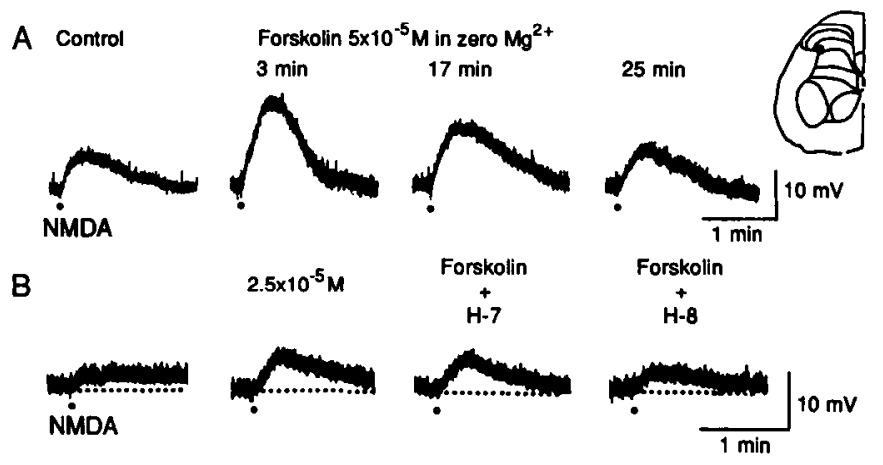

Figure 9. In a $\mathrm{Mg}^{2+}$-free solution, forskolin enhances the sensitivity of a dorsal horn neuron to NMDA in a dose-dependent manner $(A, B)$, and the effect is reduced by $\mathrm{H}-8(B)$. $A$, First trace represents control response of a dorsal horn neuron to NMDA; second, third, and fourth traces, responses at 3,17 , and $25 \mathrm{~min}$ after the onset of the bath application of forskolin $\left(5 \times 10^{-5} \mathrm{M}, 1 \mathrm{~min}\right)$, respectively. $B$, First trace is a control response to NMDA; second trace, response recorded 3 min after forskolin $\left(2.5 \times 10^{-5} \mathrm{M}, 1 \mathrm{~min}\right)$; third trace, response obtained 3 min after a combined application of forskolin $\left(2.5 \times 10^{-5} \mathrm{M}, 1 \mathrm{~min}\right)$ and $\mathrm{H}-7\left(2 \times 10^{-5} \mathrm{M}, 3 \mathrm{~min}\right)$; and fourth trace, response obtained at 3 min after application of forskolin $\left(2.5 \times 10^{-5} \mathrm{M}, 1 \mathrm{~min}\right)$ and $\mathrm{H}-8(2 \times$ $\left.10^{-5} \mathrm{M}, 3 \mathrm{~min}\right) . \mathrm{H}-7$ and $\mathrm{H}-8$ preceded and followed forskolin application for $1 \mathrm{~min}$. NMDA was applied by pressure ejection (NMDA $10^{-3} \mathbf{M}$, $0.14 \mathrm{sec}, 0.39 \mathrm{kPa}$ ). Inset, Approximate location of the tested cell. $V_{m}$, $-65 \mathrm{mV}$. 20-d-old rat. 
One mechanism that could account for the enhancement of excitatory synaptic transmission produced by phorbol esters in the spinal dorsal horn is that the nerve terminals increase secretion of neurotransmitters on PKC activation as do other secreting non-neural (Knight and Baker, 1983; Pocotte et al., 1985) and neural cells (Tanaka et al., 1984; Osses et al., 1986, Feuerstein et al., 1987; Haimann et al., 1987; Shapira et al., 1987; Versteeg and Florijn, 1987). We have presented both electrophysiological and neurochemical data showing that phorbol esters enhance the basal and depolarization-evoked release of endogenous amino acids, including putative excitatory (glutamate and aspartate) and inhibitory (GABA, glycine) synaptic mediators from the rat dorsal horn slices. In agreement with our data that phorbol esters enhance the frequency of "the spontaneous" EPSPs (Fig. 2A) are the results observed at the vertebrate neuromuscular junction (Publicover, 1985; Eusebi et al., 1986; Murphy and Smith, 1987) and in the rat hippocampal slices (Malenka et al., 1987). Enhancement in basal (Publicover, 1985; Eusebi et al., 1986; Aniksztejn et al., 1987; Malenka et al., 1987) and evoked release of various putative transmitters (glutamate, $\mathrm{ACh}$, dopamine, norepinephrine, 5-HT) caused by phorbol esters has been also reported (Zurgil and Zisapel, 1985; Allgaier and Hertting, 1986; Allgaier et al., 1986, 1988; Lynch $\&$ Bliss, 1986; Feuerstein et al., 1987). These effects of phorbol esters appear to be mediated by the activation of PKC since inactive phorbol analogs have no effect on synaptic transmission (Kuo et al., 1980; Castagna et al., 1982), although an action of phorbol esters independent of PKC cannot be ruled out entirely (Bell et al., 1985; Hollingsworth et al., 1985; Fink et al., 1988). Other possible explanations for the modulatory effects of phorbol cstcrs such as blockade of the uptakc systcms for ncurotransmitters or interference with the autoreceptor-mediated negative-feedback circuits have been excluded in some studies.

The precise biochemical mechanism underlying the enhancement of transmitter release produced by phorbol esters is as yet unclear. There is evidence that kinase $C$ activation enhances the $\mathrm{Ca}^{2+}$ sensitivity of the secretory process in non-neural cells (Knight and Baker, 1983; Pocotte et al., 1985), although it is not clear whether the enzyme is a mediator or modulator of secretion. The evidence for the role of PKC in neurotransmitter release is less compelling. Augustine et al. (1986) suggested that the enhancing effect of kinase $\mathrm{C}$ activation at the squid giant synapse may be due to a broadening of the presynaptic action potential because of a decrease in $\mathrm{K}^{+}$conductance. The spikebroadening effect of phorbol esters seen in the rat dorsal horn cells, and also in the $\mathrm{CA}_{1}$ hippocampal pyramidal cells (Storm, 1987), may contribute to the enhancement of synaptic transmission caused by phorbol esters, provided a similar mechanism operates in the synaptic terminals. Thus, a prolonged spike in the synaptic terminal will allow more influx of $\mathrm{Ca}^{2+}$ ions during the action potential, and this will in turn lead to the increased release of transmitter. Other possible mechanisms involved include diminished sequestration of internal $\mathrm{Ca}^{2+}$ or its release from internal stores (Nishizuka, 1986), increase of $\mathrm{Ca}^{3+}$ influx through voltage-dependent $\mathrm{Ca}^{2+}$ channels (DeRiemer et al., 1985; Lipscombe et al., 1988, but see Rane and Dunlap, 1986), or changes in the properties of the $\mathrm{Ca}^{2+}$-activated $\mathrm{K}^{+}$channels (Baraban et al., 1985; Malenka et al., 1986b). The phosphorylation of nerve terminal proteins involved in vesicle secretion may be a mechanism of the PKC-augmenting action in the neurotransmitter release. The presence of a presynaptically located PKC (Girard et al., 1985) and the phosphorylation of several brain proteins, including an $87 \mathrm{kDa}$ substrate by PKC during depolarization, has been demonstrated (Wu et al., 1982). Phosphorylation of the $87 \mathrm{kDa}$ substrate by phorbol ester-activated PKC in synaptosomes occurs in parallel with the enhancement of stimulation-elicited neurotransmitter release (Nichols et al., 1987). In addition, high- $\mathrm{K}^{+}$-evoked increase of neurotransmitter release in the hippocampus correlates well with the degree of phosphorylation of B-50 protein (Versteeg and Florijn, 1987).

Experimental evidence presently available suggests involvement of glutamate (and its analogs) in mediating a fast excitatory synaptic transmission in the mammalian CNS, including the rat spinal cord (Cotman and Iversen, 1987; Mayer and Westbrook, 1987). Participation of both NMDA and non-NMDA receptors in the generation of fast spinal EPSPs has been demonstrated (Mayer and Westbrook, 1987; Gerber et al., 1988).

The NMDA receptor-ion channel system is well characterized at single-channel level (Nowak et al., 1984) and exhibits several properties: (1) The NMDA channels are blocked by $\mathrm{Mg}^{2+}$ in a voltage-dependent manner (Mayer et al., 1984; Nowak et al., 1984), and the block is relieved when the membrane is strongly depolarized. (2) The channels are permeable to $\mathrm{Ca}^{2+}$ (MacDermott et al., 1986). (3) The response to NMDA is potentiated by glycine (Johnson \& Ascher, 1987).

Assuming a similar voltage-dependence of the NMDA receptor-channel system in the rat spinal dorsal horn neurons to that determined for embryonic cultured spinal neurons (Nowak et al., 1984; Mayer and Westbrook, 1985), the increase in the NMDA response of the dorsal horn cells may have been expected due to removal of $\mathrm{Mg}^{2+}$ block by the phorbol esterinduced depolarization. Ilowever, we think that this mechanism is unlikely since the enhanced NMDA response was observed in cells that showed little membrane depolarization and also in those where the depolarization was limited by current injection.

The functional importance of the glycine potentiation of the NMDA response depends on the simultaneous presence of an endogenous NMDA agonist (e.g., glutamate, aspartate) and glycine at NMDA receptors. Since we have shown that phorbol esters produce a simultaneous, although brief, increase in the basal and electrically evoked release of glutamate, aspartate, glycine, and serine from the spinal slices, the potentiation of NMDA response of dorsal horn neurons may, at least in part, be explained by this finding. In cultured spinal neurons the NMDA and glutamate responses were found to be strongly potentiated by glycine concentrations as low as $10 \mathrm{~nm}$ (Johnson and Ascher, 1987) and the response of the rat dorsal horn neurons, acutely isolated (Murase et al., 1989) or in the spinal slice (unpublished observations), by $100 \mathrm{~nm}$ glycine. Therefore, the concentration of glycine of about $10^{-7} \mathrm{M}$ found in the spinal perfusate after addition of phorbol esters, which probably reflects the elevated levels of glycine in the extracellular space, may be sufficient to account for the enhancement of the NMDA receptor activity in the present experiments. An elevated level of extracellular glycine may potentiate the effect of glutamate released at a glutaminergic synapse, and this in turn may lead to potentiation of the NMDA receptor-mediated component of compound EPSPs in the spinal dorsal horn. Because a high percentage of acutely isolated rat spinal dorsal horn neurons respond to NMDA (Murase et al., 1989), variation in the concentration of endogenous EAAs and glycine could significantly influence excitatory synaptic transmission.

Our measurements of the membrane input resistance of dorsal 
horn neurons after the application of phorbol esters did not show consistent and significant changes that can explain either magnitude or duration of the enhanced excitatory synaptic transmission. Although the soma input resistance remained virtually unchanged, we cannot rule out an increased dendritic membrane resistance as the contributing factor for the EPSP increase. Application of phorbol esters has been shown to block a Ca ${ }^{2+}$-activated $\mathrm{K}^{+}$current, and a $\mathrm{Cl}^{-}$current (Baraban et al., 1985; Madison et al., 1986). Therefore, the expected increased dendritic resistance as a result of blockade of these conductances could also explain in part the increase in EPSP observed in the present experiments. Phorbol esters, in addition, may increase voltage-dependent $\mathrm{Ca}^{2+}$ current (DeRiemer et al., 1985; Lipscombe et al., 1988) and $\mathrm{Ca}^{2+}$ influx through voltage-dependent $\mathrm{Ca}^{2+}$ channels. $\mathrm{Ca}^{2+}$ may exert its influence on synaptic function through the activation of $\mathrm{PKC}$, and it is therefore significant that Ca-dependent PKC injected directly into hippocampal pyramidal cells caused a prolonged potentiation of synaptic transmission (Hu et al., 1987).

Although in our experiments activators of PKC (phorbol esters, OAG) enhanced the sensitivity of NMDA receptors of the rat spinal dorsal horn neurons, the identity of endogenous substance(s) participating in the effect is presently unknown. The fact that PKC has non-neuronal localization in the rat spinal dorsal horn (Mochly-Rosen et al., 1987) makes interpretation of our results in terms of activation of PKC at present even more difficult. Therefore, attempts are currently being undertaken to seek candidates for endogeneous activators in other second-messenger neuronal systems that may be influenced by bath administration of activators of PKC (Berridge, 1987).

It is known that activation of PKC can enhance the accumulation of cAMP (Bell et al., 1985; Hollingsworth et al., 1985), including that elicited by forskolin or cholera toxin (Rozengurt et al., 1987), but the molecular basis of the enhancement remains poorly understood. The cAMP system is known to be capable of regulating various physiological properties of neurons, including synaptic transmission (Shuster et al., 1985), through phosphorylation of ion channels and other cellular components by cAMP-dependent kinase (Nestler and Greengard, 1983).

It is also known that glutamate receptors can regulate the production of cAMP, cGMP and metabolites of arachidonic acid in central neurons (Ferrendelli et al., 1974; Garthwaite, 1982; Pellerin and Wolfe, 1988). It is, therefore, of interest that we recently observed that the bath administration of forskolin, an adenylate cyclase activator, enhances the sensitivity of the NMDA-type glutamate receptors of the immature rat dorsal horn neurons and that this effect was reduced by $\mathrm{H}-8$, an inhibitor of cAMP-dependent protein kinase (Hikada et al., 1984).

Our results suggest that in the rat spinal dorsal horn PKC may have a role in controlling the release of putative neurotransmitters and may also be involved in the regulation of sensitivity of postsynaptic NMDA receptors, but the identity of endogenous substance(s) participating in these effects is presently unknown. Our preliminary finding of a comparable potentiating action of the phorbol esters and forskolin on NMDA receptors suggests that phorbol esters perhaps do increase cAMP levels (Rozengurt et al., 1987) which are ultimately responsible for the enhanced NMDA responses.

\section{References}

Allgaier, C., and G. Hertting (1986) Polymyxin B, a selective inhibitor of protein kinase $\mathrm{C}$, diminishes the release of noradrenaline and the enhancement of release caused by phorbol 12,13-dibutyrate. Naunyn Schmiedebergs Arch. Pharmacol. 334: 218-221.

Allgaier, C., O. Von Kugelgen, and G. Hertting (1986) Enhancement of noradrenaline release by 12- $O$-tetradecanoyl phorbol-13-acetate, an activator of protein kinase C. Eur. J. Pharmacol. 129: 389-392.

Allgaier, C., B. Daschmann, H. Y. Huang, and G. Hertting (1988) Protein kinase $\mathrm{C}$ and presynaptic modulation of acctylcholine release in rabbit hippocampus. Br. J. Pharmacol. 93: 525-534.

Aniksztejn, L., M.-P. Roisin, H. Gozlan, and Y. Ben-Ari (1987) Longlasting potentiation produced by a phorbol ester in the hippocampus of the anesthesized rat is not associated with a persistent enhanced release of excitatory amino acids. Neurosci. Lett. 81: 291-295.

Augustine, G. J., L. R. Osses, S. R. Barry, and M. P. Charlton (1986) Presynaptic mechanism of kinase $\mathrm{C}$ activators at the squid giant synapse. Soc. Neurosci. Abstr. 12:821.

Baraban, J. M., S. H. Snyder, and B. E. Alger (1985) Protein kinase $C$ regulates ionic conductance in hippocampal pyramidal neurons: Electrophysiological effects of phorbol esters. Proc. Natl. Acad. Sci. USA 82: 2538-2542.

Bell, J. D., I. L. O. Buxton, and L. L. Brunton (1985) Enhancement of adenylate cyclase activity in $\$ 49$ lymphoma cells by phorbol estcrs. Putative effect of $\mathrm{C}$ kinase on alpha s-GTP-catalytic subunit interaction. J. Biol. Chem. 260: 2625-2628.

Berridge, M. J. (1987) Inositol trisphosphate and diacylglycerol: Two interacting second messengers. Annu. Rev. Biochem. 56: 159-193.

Berridge, M. J., and R. F. Irvine (1984) Inositol triphosphate, a novel second messenger in cellular signal transduction. Nature 312: 315321.

Castagna, M., Y. Takai, K. Kaibuchi, K. Sano, U. Kikkawa, and Y. Nishizuka (1982) Direct activation of calcium-activated, phospholipid-dependent protein kinase by tumor-promoting phorbol esters. J. Biol. Chem 257: 7847-7851

Cotman, C. W., and L. L. Iversen (1987) Excitatory amino acids in the brain-focus on NMDA receptors. Trends Neurosci. 10: 263265.

DeRiemer, S. A., J. A. Strong, K. A. Albert, P. Greengard, and L. K. Kaczmarek (1985) Enhancement of calcium current in Aplysia neurones by phorbol ester and protein kinase C. Nature 313:313-316.

Eusebi, F., M. Molinaro, and C. G. Caratsch (1986) Effects of phorbol ester on spontaneous transmitter release at frog neuromuscular junction. Pfluegers Arch. 406: 181-183.

Ferrendelli, J. A., M. M. Chang, and D. A. Kinscherf (1974) Elevation of cyclic GMP levels in central nervous system by excitatory and inhibitory amino acids. J. Neurochem. 22: 535-540.

Feuerstein, T. J., C. Allgaier, and G. Hertting (1987) Possible involvement of protein kinase $\mathrm{C}(\mathrm{PKC})$ in the regulation of electrically evoked serotonin (5-HT) release from rabbit hippocampal slices. Eur. J. Pharmacol. 139: 267-272.

Fink, D. W., Jr., M. L. Contreras, and G. Guroff (1988) Nerve growth factor (NGF) stimulates the release of arachidonic acid (AA) from PC12 cells. Soc. Neurosci. Abstr. 14: 684.

Garthwaite, J. (1982) Excitatory amino acid receptors and guanosine $3^{\prime}, 5^{\prime}$-cyclic monophosphate in incubated slices of immature and adult rat cerebellum. Neuroscience 7: 2491-2497.

Gerber, G., P. D. Ryu, and M. Randic (1987) Multiple effects of activation of protein kinase $\mathrm{C}$ in the rat spinal dorsal horn. Soc. Neurosci. Abstr. 13: 107.

Gerber, G., P. D. Ryu, and M. Randic (1988) Phorbol esters enhance responsiveness of rat dorsal horn neurons to N-methyl-D-aspartic acid. Soc. Neurosci. Abstr. 14: 96.

Girard, P. R., G. J. Mazzei, J. G. Wood, J. F. Kuo (1985) Polyclonal antibodies to phospholipid/ $\mathrm{Ca}^{2+}$ dependent protein kinase and immunocytochemical localization of the enzyme in rat brain. Proc. Natl. Acad. Sci. USA 82: 3030-3034.

Gispen, W. H., J. L. M. Leunissen, A. B. Oestreicher, A. J. Verkleij, and $H$. Zwiers (1985) Presynaptic localization of B-50 phosphoprotein: The (ACTH)-sensitive protein kinase substrate involved in rat brain polyphosphoinositide metabolism. Brain Res. 328:381-385.

Haimann, C., J. Meldolesi, and B. Ceccarelli (1987) The phorbol ester, 12-0-tetradecanoyl-phorbol-13-acetate, enhances the evoked quanta release of acetylcholine at the frog neuromuscular junction. Pfluegers Arch. 408: 27-31.

Hidaka, H., M. Inagaki, S. Kawamoto, and Y. Sasaki (1984) Isoquinoline-sulfonamides, novel and potent inhibitors of cyclic nucleotide dependent protein kinase and protein kinase C. Biochemistry 23: 5036-5041. 
Hollingsworth, E. B., E. B. Sears, and J. W. Daly (1985) An activator of protein kinase $C$ (phorbol-12-myristate-13-acetate) augments 2-chloroadenosine-elicited accumulation of cyclic AMP in guinea pig cerebral cortical particulate preparations. FEBS Lett. 184: 339-342.

Hu, G.-Y., O. Hvalby, S. I. Walaas, K. A. Albert, P. Skjeflo, P. Andersen, and P. Greengard (1987) Protein kinase C injection into hippocampal pyramidal cells elicits features of long term potentiation. Nature 328: $426-429$

Inoue, M., A. Kishimoto, Y. Takai, and Y. Nishizuka (1977) Studies on a cyclic nucleotide-independent protein kinase and its proenzyme in mammalian tissues. J. Biol. Chem. 252: 7610-7616.

Johnson, J. W., and P. Ascher (1987) Glycine potentiates the NMDA response in cultured mouse brain neurones. Nature 325: 529-531.

Kangrga, I., J. S. A. Larew, and M. Randic (1989) The effects of substance $P$ and calcitonin gene-related peptide on the efflux of endogenous glutamate and aspartate from the rat spinal dorsal horn in vitro. Neurosci. Lett. (in press)

Kishimoto, A., Y. Takai, T. Mori, U. Kikkawa, and Y. Nishizuka (1980) Activation of calcium and phospholipid-dependent protein kinase by diacylglycerol, its possible relation to phosphatidylinositol turnover. J. Biol. Chem. 255: 2273-2276.

Knight, D. E., and P. F. Baker (1983) The phorbol ester TPA increases the affinity of exocytosis for calcium in "leaky" adrenal medullary cells. FEBS Lett. 160: 98-100.

Kristjansson, G. I., H. Zwiers, A. B. Oestreicher, and W. H. Gispen (1982) Evidence that the synaptic phosphoprotein B-50 is localized exclusively in nerve tissue. J. Neurochem. 39: 371-378.

Kuo, J. F., R. G. Anderson, B. C. Wise, L. Mackerlova, I. Salomonsson, N. L. Brackett, N. Katoh, M. Shoji, and R. W. Wrenn (1980) Calcium-dependent protein kinase: Widespread occurrence in various tissues and phyla of the animal kingdom and comparison of effects of phospholipid, calmodulin, and trifluoperazine. Proc. Natl. Acad. Sci. USA 77: 7039-7043.

Lindroth, P., and K. Mopper (1979) High performance liquid chromatographic determination of subpicomole amounts of amino acids by precolumn fluorescence derivatization with $\mathrm{O}$-phthaldialdehyde. Anal. Chem. 51: 1667-1674.

Lipscombe, D., K. Bley, and R. W. Tsien (1988) Modulation of Ca channels by cAMP and phorbol esters. Soc. Neurosci. Abstr. 64: 153.

Lynch, M. A., and T. V. P. Bliss (1986) Long-term potentiation of synaptic transmission in the hippocampus of the rat; effect of calmodulin and oleoyl-acetyl-glycerol on release of $\left[{ }^{3} \mathrm{H}\right]$-glutamate. Neurosci. Lett. 65: 171-176.

MacDermott, A. B., M. L. Mayer, G. L. Westbrook, S. J. Smith, and J. L. Barker (1986) NMDA-receptor activation increases cytoplasmic calcium concentration in cultured spinal cord neurones. Nature 321: 519-522.

Madison, D. V., R. C. Malenka and R. A. Nicoll (1986) Phorbol esters block a voltage-sensitive chloride current in hippocampal pyramidal cells. Nature 321: 695-697.

Malenka, R. C., D. V. Madison, and R. A. Nicoll (1986a) Potentiation of synaptic transmission in the hippocampus by phorbol esters. Nature 321: 175-177.

Malenka, R. C., D. V. Madison, R. Andrade, and R. A. Nicoll (1986b) Phorbol esters mimic some cholinergic actions in hippocampal pyramidal neurons. J. Neurosci. 6:475-480.

Malenka, R. C., G. S. Ayoub, and R. A. Nicoll (1987) Phorbol esters enhance transmitter release in rat hippocampal slices. Brain Res. 403: 198-203.

Mantyh, P. W., R. D. Pinnock, C. P. Downes, M. Goedert, and S. P. Hunt (1984) Correlation between inositol phospholipid hydrolysis and substance $P$ receptors in rat CNS. Nature 309: 795-797.

Mayer, M. L., and G. L. Westbrook (1985) The action of N-methylD-aspartic acid on mouse spinal neurones in culture. J. Physiol. (Lond.) 361: 65-90.

Mayer, M. L., and G. L. Westbrook (1987) The physiology of excitatory amino acids in the vertebrate central nervous system. Prog. Neurobiol. 28: 197-276.

Mayer, M. L., G. L. Westbrook, and P. B. Guthrie (1984) Voltagedependent block by $\mathrm{Mg}^{2+}$ of NMDA responses in spinal cord neurones. Nature 309: 261-263.

Mochly-Rosen, D., A. I. Basbaum, and D. E. Koshland, Jr. (1987) Distinct cellular and regional localization of immunoreactive protein kinase C in rat brain. Proc. Natl. Acad. Sci. USA 84: 4660-4664.
Murase, K., and M. Randic (1983) Electrophysiological properties of rat spinal dorsal horn neurones in vitro-calcium dependent action potentials. J. Physiol. (Lond.) 334: 141-153.

Murase, K., P. D. Ryu, and M. Randic (1989) Excitatory and inhibitory amino acids and peptide-induced responses in acutely isolated rat spinal dorsal horn neurons. Neurosci. Lett. 89: 305-312.

Murphy, R. L. W., and M. E. Smith (1987) Effects of diacylglycerol and phorbol ester on acetylcholine release and action at the neuromuscular junction in mice. Br. J. Pharmacol. 90: 327-334.

Nestler E. J. and P. Greengard (1983) Protein phosphorylation in the brain. Nature 305: 583-588.

Nichols, K. A., J. W. Haycock, J. K. T. Wang, and P. Greengard (1987) Phorbol ester enhancement of neurotransmitter release from rat brain synaptosomes. J. Neurochem 48: 615-621.

Nishizuka, Y. (1984) Turnover of inositol phospholipids and signal transduction. Science 225: 1365-1370.

Nishizuka, Y. (1986) Studies and perspectives of protein kinase C. Science 233: 305-312.

Nowak, L., P. Bregestovski, P. Ascher, A. Herbert, and A. Prochiantz (1984) Magnesium gates glutamate-activated channels in mouse central neurones. Nature 307: 462-465.

Osses, L., S. Barry, G. Augustine, and M. Charlton (1986) Protein kinase $\mathrm{C}$ activation enhances transmission at the squid giant synapse. Biophys. J. 49: 179a.

Pellerin, L., and L. S. Wolfe (1988) Glutamate induces 12-HETE synthesis through NMDA receptor activation in rat cerebral cortex. Soc. Neurosci. Abstr. 14:131.

Pocotte, S. L., R. A. Frye, R. A. Senter, D. R. Ter Bush, S. A. Lee, and R. W. Holtz (1985) Effects of phorbol ester on catecholamine secretion and protein phosphorylation in adrenal medullary cell cultures. Proc. Natl. Acad. Sci. USA 82: 930-934.

Publicover, S. J. (1985) Stimulation of spontaneous transmitter release by the phorbol ester, 12-O-tetradecanoyl-phorbol-13-acetate, an activator of protein kinase C. Brain Res. 333: 185-187.

Rane, S. G., and K. Dunlap (1986) Kinase C activator 1,2-oleoylacetylglycerol attenuates voltage-dependent calcium current in sensory neurones. Proc. Natl. Acad. Sci. USA 83: 184-188.

Rodnight, R., and C. Perrett (1986) Protein phosphorylation and synaptic transmission: Receptor mediated modulation of protein kinase $\mathrm{C}$ in a rat brain fraction enriched in synaptosomes. J. Physiol. (Paris) 81: $340-348$.

Rozengurt, E., M. Murray, I. Zachary, and M. Collins (1987) Protein kinase $C$ activation enhances cAMP accumulation in Swiss 3 T3 cells: Inhibition by pertussis toxin. Proc. Natl. Acad. Sci. USA 84: 22822286.

Shapira, R., S. D. Silberberg, S. Ginsburg, and R. Rahamimoff (1987) Activation of protein kinase $\mathrm{C}$ augments evoked transmitter release. Nature 325: 58-60.

Shuster, M. J., J. S. Camardo, S. A., Siegelbaum, and E. R. Kandel (1985) Cyclic AMP-dependent protein kinase closes the serotonin sensitive $\mathrm{K}^{+}$-channels of Aplysia sensory neurons in cell-free membrane patches. Nature 313: 392-395.

Sorensen, R. G., L. P. Kleine, and H. R. Mahler (1981) Presynaptic localization of phosphoprotein B-50. Brain Res. Bull. 7: 57-61.

Storm, J. F. (1987) Phorbol esters broaden the action potential in CA1 hippocampal pyramidal cells. Neurosci. Lett. 75: 71-74.

Takai, Y., A. Kishimoto, Y. Iwasa, Y. Kawahara, T. Mori, and Y. Nishizuka (1979) Calcium-dependent activation of a multifunctional protein kinase by membrane phospholipids. J. Biol. Chem. 254: 3692-3695.

Tanaka, C., K. Taniyama, and M. Kusunoki (1984) A phorbol ester and A23187 act synergistically to release acetylcholine from the guinea pig ileum. FEBS Lett. 175: 165-169.

Urban, L., and M. Randic (1984) Slow excitatory transmission in rat dorsal horn: Possible mediation by peptides. Brain Res. 290: 336341.

Usherwood, P. N. R. (1978) Amino acids as neurotransmitters. Adv. Comp. Physiol. Biochem. 7: 227-309.

Versteeg, D. H. G., and W. J. Florijn (1987) Phorbol 12, 13-dibutyrate enhances electrically stimulated neuromessenger release from rat dorsal hippocampal slices in vitro. Life Sci. (Oxford) 40: 1237-1243

Watkins, J. C., and R. H. Evans (1981) Excitatory amino acid transmitters. Annu. Rev. Pharmacol. Toxicol. 21: 165-204.

Werz, M. A., and R. L. Macdonald (1987) Phorbol esters: Voltage- 
dependent effects on calcium-dependent action potentials of mouse central and peripheral neurons in cell culture. J. Neurosci. 7: 16391647.

Wood, J. G., P. R. Girard, G. J. Mazzei, and J. F. Kuo (1986) Immunocytochemical localization of protein kinase $C$ in identified neuronal compartment of rat brain. J. Neurosci. 6: 2571-2577.

Worley, P. F., I. M. Baraban, and S. H. Snyder (1986a) Heterogenous localization of protein kinase $\mathrm{C}$ in rat brain: Autoradiographic analysis of phorbol ester receptor binding. J. Neurosci. 6: 199-207.

Worley, P. F., J. M. Baraban, E. B. De Souza, and S. H. Snyder (1986b) Mapping second messenger systems in the brain: Differential localizations of adenylate cyclase and protein kinase C. Proc. Natl. Acad. Sci. USA 83: 4053-4057.

Wu, W. C., S. I. Walaas, A. C. Nairn, and P. Greengard (1982) Calcium/phospholipid regulates phosphorylation of a $\mathrm{Mr}$ " 87 " substrate protein in brain synaptosomes. Proc. Natl. Acad. Sci. USA 79: 52495253.

Yamamoto, D. (1988) Activation of protein kinase C promotes glutamate-mediated transmission at the neuromuscular junction of the mealworm. J. Physiol. (Lond.) 400: 691-700.

Yamamoto, D., and H. Washio (1980) L-glutamate as an excitatory transmitter at the neuromuscular junction of a beetle larva. J. Insect Physiol 26: 253-256.

Zhang, L., and K. Krnjevic (1987) Effects of intracellular injections of phorbol ester and protein kinase $\mathrm{C}$ on cat spinal motoneurons in vivo. Neurosci. Lett. 77: 287-292.

Zurgil, N., and N. Zisapel (1985) Phorbol esters and calcium act synergistically to enhance neurotransmitter release by brain neurons in culture. FEBS Lett. 185: 257-261. 